\title{
Challenges and facilitators for health practitioners and academics engaging in collaborative research and publication: A systematic review Herausforderungen und Förderfaktoren für gemeinsame Forschung und wissenschaftliche Publikation von Angehörigen verschiedener Gesundheitsberufe aus Praxis und Forschung: ein systematischer Review
}

\author{
Lindy King ${ }^{1 *}$, Tatjana Zlatanovic ${ }^{2}$, David Gillham \\ ${ }^{1}$ Flinders University, College of Nursing and Health \\ Sciences, 5001 Adelaide AUSTRALIA \\ ${ }^{2}$ Oslo and Akershus University College of Applied Sciences, \\ Centre for the Study of Professions, 0130 Oslo, NORWAY \\ *lindy.king@flinders.edu.au
}

Received 12 April 2018, accepted 24 July 2018

\begin{abstract}
Introduction: While academics are frequently engaged in research activities and subsequent dissemination of results through publication, all too often they occur without health practitioner involvement. While there are contemporary expectations that health practitioners will be active contributors to their discipline's body of knowledge, many find it difficult to prioritise research involvement given the demands of direct patient care. With this awareness as a central focus, we undertook a literature review to identify the challenges and facilitators that impact on health practitioners and academics working collaboratively on research and publishing their findings in peer-reviewed journals.

Methods: A configurative systematic review was performed with six electronic databases (Proquest, CINAHL, Medline, ScienceDirect, ERIC, SocINDEX) searched for studies from the disciplines of nursing, social work, allied health professions, health management, psychology and sociology. Manual searches were also undertaken to minimise the risk of missed studies. A rigorous search and retrieval process identified 20 relevant studies for inclusion in the review. The studies were first critically appraised then summarised. These steps were followed by thematic synthesis of the findings of the reviewed studies.

Results: Challenges and facilitators to health practitioners and academics working collaboratively on research activities were found to be related to the interplay between practitioners, academics, educational and health institutions and professional demands. The interplay of these factors emerged as complex.

Conclusion: Strategies have been recommended that may encourage active partnerships between institutions, health practitioners
\end{abstract} and academics enabling greater research collaborations and subsequent increased publication of their combined achievements.

\section{Abstract}

Einleitung: Während Akademiker häufig mit Forschungsaktivitäten und der anschließenden Verbreitung von Ergebnissen durch Veröffentlichungen befasst sind, geschieht dies allzu oft ohne Beteiligung von Healthprofessionals aus der Praxis. Zwar gibt es die Erwartung, dass Healthprofessionals aktiv zum Wissensschatz ihrer Disziplin beitragen, es ist jedoch schwierig, dies mit den Anforderungen der direkten Patientenversorgung zu verbinden. Dies war der Ausgangspunkt für eine Literaturrecherche, um Herausforderungen und Förderfaktoren zu identifizieren, die sich auf Healthprofessionals in der Praxis und Wissenschaftler auswirken, die gemeinsam an Forschung arbeiten und ihre Ergebnisse in Fachzeitschriften veröffentlichen.

Methode: Mit sechs elektronischen Datenbanken (Proquest, CINAHL, Medline, Science Direct, ERIC, SocINDEX) wurde ein systematischer Review durchgeführt, der nach Studien aus den Bereichen Pflege, Sozialarbeit, Gesundheitsberufe, Gesundheitsmanagement, Psychologie und Soziologie suchte. Es wurden auch manuelle Recherchen durchgeführt, um das Risiko verpasster Studien zu minimieren. Ein rigoroser Such- und Retrieval-Prozess identifizierte 20 relevante Studien für die Aufnahme in den Review. Diese Studien wurden kritisch bewertet, zusammengefasst und anschließend wurde eine thematische Synthese ihrer Ergebnisse vorgenommen.

Ergebnisse: Es stellte sich heraus, dass Herausforderungen und Förderfaktoren für Gesundheitspraktiker und Wissenschaftler, die gemeinsam an Forschungsaktivitäten arbeiten, sich auf das Zusammenspiel zwischen Praktikern, Akademikern, Bildungs- und Gesundheitseinrichtungen und professionellen Anforderungen beziehen. Das Zusammenspiel dieser Faktoren erwies sich als komplex.

Schlussfolgerungen: Es wurden Strategien empfohlen, die aktive Partnerschaften zwischen Institutionen, Gesundheitspraktikern und Akademikern fördern könnten, um größere Forschungskooperationen zu ermöglichen und deren gemeinsame Erfolge zu erhöhen.

\section{Keywords}

Academics - Collaboration - Educational institutions - Health institutions - Literature review - Health practitioners - Research - Publishing

\section{Keywords}

Akademiker - Zusammenarbeit - Bildungsinstitutionen - Gesundheitseinrichtungen - Review - Gesundheitspraktiker - Forschung - Veröffentlichung 


\section{INTRODUCTION/BACKGROUND}

Health professionals need to manage the challenging and intense contemporary workplace by developing strong levels of clinical expertise (Benner et al., 2010). However, unless undertaking postgraduate studies, there are few opportunities for these practitioners to find time to publish and thus share their knowledge with others (King et al., 2017). University-based academics of health-related disciplines, on the other hand, are actively encouraged to publish frequently and given greater opportunities to access and participate in research. We used the term "academic" broadly to include those employed in universities undertaking either teaching or research or a combination of these activities. While academics' roles vary, there is a risk over time of some academics becoming less connected with their practitioner colleagues and the health care workplace (Benner et al., 2010). This disconnection is problematic as the current evidence-based knowledge is critical to professional expertise (Evans et al., 2014). Research knowledge is best developed through collaborative activities between practitioners and academics through a genuine nexus of research, education and practice.

While professional or discipline knowledge can be heterogeneous and highly fragmented (Grimen, 2008), it must be grounded in advanced theory and research (Freidson, 2001) and highly integrated into practical situations. Professional problem-solving in today's health and educational systems requires the use of evidence-based practice (EBP), research involvement and participation in communities of practice (Bereiter \& Scardamalia, 1993; Engestrom, 2008). However, participation in research and integration of researchbased knowledge into practice requires considerable time, significant intellectual effort and support (Eraut, 1994). When considering the relationship between different professional contexts and views of academics and practitioners on research, knowledge development and knowledge use, Eraut (1985) offered a classic and yet very current observation:

"in some professions nearly all new practice is both invented and developed in the field, with the role of academics being confined to that of dissemination, evaluation and post-hoc construction of theoretical rationales. In others, knowledge is developed by practitioners 'solving' individual cases and problems, contributing to their personal store of experience and possibly that of their colleagues but not being codified, published or widely disseminated." (Eraut 1985, p. 129)

As a process of dissemination of the results of research activities, publishing greatly improves access to current knowledge and efficiency of communication. Publishing in peer-reviewed journals facilitates the impartial assessment of research and provides the last stage in securing high-quality distribution of information. In the light of contemporary health service and educational institution contexts, it could be argued that publishing more than ever should be a requirement in professional advancement.

Given the abovementioned concerns, we performed a systematic review, focusing on the following research question:

What are the facilitators and challenges to health practitioners working collaboratively with academics to undertake research and publish their findings in peerreviewed journals?

\section{Conceptual Framework}

The process of collaboration and participation in research and publishing is complex and depends on many prerequisites (King et al., 2015). These fundamentals can include the following: the level of research-oriented training; training in (academic) writing; the gratification systems for academics and thus the rewards for engaging in practitioner-based research; educational policy and epistemic beliefs about the nature of knowledge and knowing (Markauskaite \& Goodyear, 2014). We structured this review within the framework of professional knowledge, EBP (Sackett, 1996) and the relationship of these concepts with the utilisation of research in practice.

The twenty-first century requires strong connections between the production of knowledge and its use in professional work. Scientific excellence is sought (Markauskaite \& Goodyear, 2014) to meet patient demands for increasing quality, efficiency, safety and satisfaction in health care. The link between professional knowledge base and academic knowledge production to provide resources for meeting the challenges of practice is clearly recognised (Abbott, 1988; Friedson, 2001). The drive for practice settings to adopt and utilise robust research knowledge and the ability of education to keep pace with rapid changes in practice are illuminated in the literature from the health professions (Benner et al., 2010; Sullivan, 2005; Staykova, 2012). Moreover, knowledge creation, innovation and transformation capacities are important qualities of successful practitioners as well as organisations (Engeström, 2008). In relation to health professions, professional competencies can only remain current if practitioners continually engage with new knowledge (Eraut, 1994; Friedson, 2001). Furthermore, practitioners need to demonstrate professional maturity to challenge accepted boundaries of practice and initiate new developments (McGee and Castledine, 2003).

EBP, as a concept, provides a basis for making decisions on approaches to health care by integrating the best available research evidence to inform practice. This concept 


\begin{tabular}{|c|c|c|}
\hline Inclusion criteria & Exclusion criteria & Rationale \\
\hline Peer-reviewed studies & $\begin{array}{l}\text { Non-peer-reviewed and/or non- } \\
\text { research articles }\end{array}$ & $\begin{array}{l}\text { To ensure scientific quality by decreasing risk for inappropriate } \\
\text { conclusions }\end{array}$ \\
\hline English & Other languages & English-speaking researchers \\
\hline Developed countries & $\begin{array}{c}\text { Studies undertaken in undeveloped or } \\
\text { countries in transition }\end{array}$ & $\begin{array}{l}\text { Lack of congruence with contemporary experiences in developed } \\
\text { countries }\end{array}$ \\
\hline $\begin{array}{l}\text { Practitioner and academic col- } \\
\text { laboration in research and/or } \\
\text { writing for publication }\end{array}$ & $\begin{array}{l}\text { Not focused on practitioner-academic } \\
\text { collaboration in research and/or writ- } \\
\text { ing for publication }\end{array}$ & $\begin{array}{l}\text { To identify the issues raised by health practitioners and academics } \\
\text { when collaborating in research activities; enablers, and challenges } \\
\text { to dissemination by publication }\end{array}$ \\
\hline Publishing period 2006-current & Studies published before 2006 & $\begin{array}{l}\text { Contemporary studies during period affected by hospital ac- } \\
\text { creditation policies seeking practitioners to publish outcomes of } \\
\text { research projects in journals }\end{array}$ \\
\hline
\end{tabular}

continues to receive significant support as it has over the past two decades (Sackett, 1996). Research evidence is integrated with practitioners' expertise and is considered alongside available resources and the characteristics, needs, values and preferences of those receiving care. EBP is widely accepted in the health professions as a way to establish a research culture for professional knowledge building and practice transformation, drawing together academics and practitioners alike. However, despite best intentions and acceptance of EBP, in practice, the objectives of this concept often lack broad implementation across disciplines and health organisations.

\section{METHODOLOGY}

The recommended stages were followed for performing a systematic review: initiation of the review by the review team, formulation of review questions and methodology, development of a search strategy, descriptions of study characteristics, quality and relevance assessment and synthesis (Gough et al., 2012).

\section{Database searches}

We conducted a comprehensive literature search of diverse databases (Figure 1) investigating the disciplines of nursing, other health professions, health management, psychology and sociology. We also performed manual searches to minimise the risk of missed studies due to electronic selection from the use of predetermined search terms (Brunton et al., 2012).

The initial keywords included health practitioners, research competencies, development, research-practice nexus, facilitators and barriers and publishing. Synonyms of these words were then determined and further arranged based on the Medical Subject Heading (MeSH) terms to identify the root terms. These root terms incorporated the following: health practitioners/professionals (non- academic); research outcomes, research-practice nexus/ research-professional practice integration; collaboration with academics/clinical and university collaboration; facilitators and barriers; publishing/publications/ dissemination of findings/communication of research evidence/writing for publications. Using the terms in various combinations yielded a substantial number of studies, as described in the following section.

\section{Selection of the studies}

In the first stage, we read the titles and keywords of the articles and selected 172 studies that matched the review question. In the second stage, we read the abstracts to consider content alongside the inclusion criteria, as presented in Table 1.

When the search was limited to defined criteria, the number of studies decreased substantially. Electronic searches showed that many studies employed the same terms but did not share the same focus (Gough et al., 2012). For those abstracts considered relevant to the review question, we retrieved the full-text articles for further reading. After excluding duplicate articles and evaluating the abstracts, 73 full-text articles remained.

After a comprehensive examination of the full-text articles, we compiled a list of the final studies to be included: 20 studies met the inclusion criteria and were included for critical appraisal. A flowchart providing a detailed illustration of the search trail is shown in Figure 1.

The application of exclusion criteria eliminated nonresearch articles as well as many studies with limited focus upon practitioner-academic collaboration in research and/or writing for publication.

\section{Critical appraisal}

Through further reading, we derived criteria for identifying and evaluating studies (Long et al., 2002). 


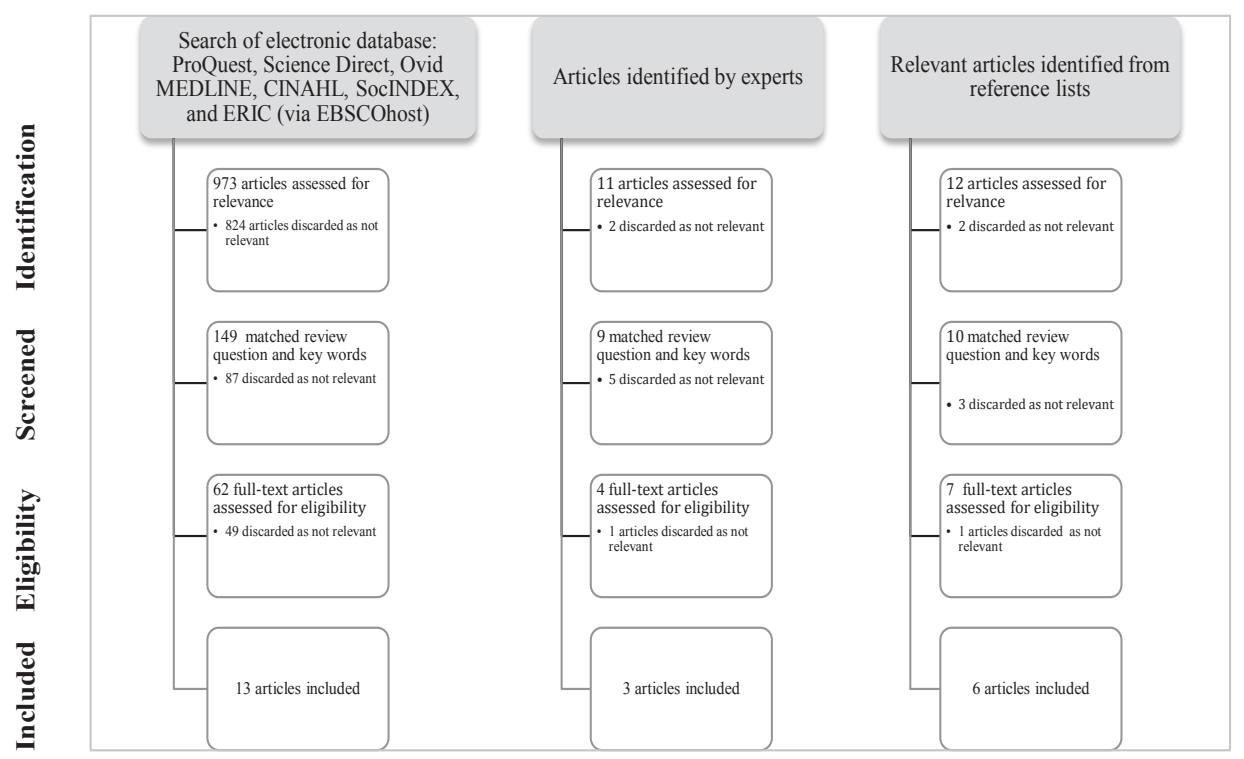

Figure 1: Flow of information through the different phases of study selection inspired by PRISMA Statement (Moher et al., 2010)

Table 2: Key questions in the critical appraisal of the studies

\begin{tabular}{ll}
\hline 1. & Are the aims / research question clearly stated? \\
\hline 2. & $\begin{array}{l}\text { Is there a clear relationship between the study and the area of } \\
\text { topic review? }\end{array}$ \\
\hline 3. & $\begin{array}{l}\text { Are theoretical/ conceptual framework used to explain, pre- } \\
\text { dict, or understand the research problem? }\end{array}$ \\
\hline 4. & $\begin{array}{l}\text { Are the methods (study design, samples, and instruments) } \\
\text { appropriate for examination for the research question? }\end{array}$ \\
\hline 5. & $\begin{array}{l}\text { Were data gathering and analysis processes described in clear } \\
\text { and sufficient detail within the study? }\end{array}$ \\
\hline 6. & Have ethical issues been adequately addressed in each study? \\
\hline 7. & Are cited sources appropriate to support the conclusions? \\
\hline 8. & Are the key points illustrated? \\
\hline 9. & Are the study's findings generalizable, or transferability high? \\
\hline 10. & Are implications for policy and service practice stated? \\
\hline
\end{tabular}

Ten highly pertinent questions from Long et al.'s evaluation tool for mixed method designs were applied to the reviewed studies (Table 2).

Further, we summarised the process of judging rigor through the epistemic quality and relevance of the studies following the Transparency, Accuracy, Purposivity, Utility, Propriety, Accessibility and Specificity (TAPUPA) framework (Pawson et al., 2003). The included studies were summarised to provide detailed information on methods and findings and their specific strengths and limitations (Appendix 1). In the relatively large body of literature that we searched, the need for practitioners to undertake writing for publication was rarely stated. The selection process ultimately resulted in 20 articles being included in the final review.

\section{Analytical approach}

Performing a configurative review principally means to arrange findings from primary research studies to answer the review question. The primary studies identified in configurative reviews can be heterogeneous and involve interpretive analysis. We applied thematic synthesis to bring together the findings from these studies that used different research designs (Thomas et al., 2012) using the following steps:

1. We began the analysis with familiarisation with the data body: reading and rereading the findings of each study allowed us to become familiar with commonalities and differences.

2. We extracted and combined the quantitative and qualitative findings from each study using Oliver and Sutcliffe's (2012) approach. We used MAXQD11 software (2015) to organise the data.

3. We analysed the qualitative studies first by comparing the authors' theme headings and illustrations of participants' perceptions. By closely examining the individual studies, we identified codes. These codes involved identification of full sentences that had consistent meanings. The codes were then organised into subcategories. We then grouped similar subcategories together.

4. Next, we assessed the mixed methods and quantitative studies. We repeated the processes of step 3 and placed the results of the coding into the emergent subcategories. 
5. We re-examined the identified subcategories to determine how they were connected. The emergent subcategories were, in this process, reduced to 11 through merging of some of the smaller subcategories. In this stage of synthesis, we also explored similarities and differences across subcategories (e.g. confidence versus support). Finally, the 11 subcategories were organised into four main themes, as described in the "Results" section.

\section{RESULTS}

\section{Summary of the reviewed studies}

The 20 studies were conducted in the developed countries of Australia, the United States, New Zealand, the United Kingdom, the Netherlands, France and Sweden. The clearly stated aims were strengths in all identified studies. Direct mention of publication or writing for publication occurred in seven studies: Finch et al. (2013); King et al. (2015); Koivula et al. (2011); Metcalf et al. (2010); Murray and Newton (2009); Probst et al. (2015) and Stephens et al. (2009), although this was explored in detail in one study only (King et al., 2015).

Ten studies have defined theoretical/conceptual foundations indicating a wide range of approaches: Bedoee (2011); Behar-Horenstein and Johnson (2010); Dupin et al. (2015); Finch et al. (2013); Gonzalez et al. (2012); Hauck et al. (2015); King et al. (2015); Koivula et al. (2011); Pager et al. (2012) and (Stephens et al., 2009). The remaining ten studies used the relevant literature as background for their research: Evans et al. (2013); Finch et al. (2015); Gerrish et al. (2011); Jansen and Hoeijmakers (2013); Janssen et al. (2015); Metcalf et al. (2010); Murray and Newton (2009); Probst et al. (2015); Rickard et al. (2011) and (Ulrich et al., 2015).

The types of research design used were clearly detailed in 13 of the studies. In total, eight studies used qualitative methods: Bedoee (2011); Behar-Horenstein and Johnson (2010); Dupin et al. (2015); Evans et al. (2013); Finch et al. (2015); Gonzalez et al. (2012); Hauck et al. (2015) and Murray and Newton (2009); seven were quantitative: Finch et al. (2013); Koivula et al. (2011); Metcalf et al. (2010); Pager et al. (2012); Probst et al. (2015); Stephens et al. (2009) and Ulrich et al. (2015) and five combined quantitative and qualitative methods: Gerrish et al. (2011); Jansen and Hoeijmakers (2013); Janssen et al. (2015), King et al. (2015) and Rickard et al. (2011). The preferred methods for data collection were fixed response and selfcompleted questionnaires. Six studies including Janssen et al. (2015); King et al. (2015); Metcalf et al. (2010); Pager et al. (2012), Probst et al. (2015) and Stephens et al. (2009) used standardised or developed instruments only. Five studies used a combination of questionnaire and qualitative methods: Gerrish et al. (2011); Jansen and Hoeijmakers (2013); Janssen et al. (2015), King et al. (2015) and Rickard et al. (2011). Six studies used a face-to-face interview only: Bedoee (2011); Dupin et al. (2015); Evans et al. (2013); Finch et al. (2015); Gonzalez et al. (2012) and Murray and Newton (2009). The sample sizes in the reviewed studies ranged from six to 40 in the qualitative studies and from six to 855 in the studies based on quantitative methodology. Although the review drew on studies including health practitioners in general, nurses were the main study participants $(1,305$ across eight of the studies).

The overall quality of studies included in the review was good with all studies meeting the requirements of the TAPUPA framework (Pawson et al., 2003). There were some limitations in relation to reporting of ethics information in the studies by Bedoee (2011), Gonzalez et al. (2012), Jansen and Hoeijmakers (2013), Koivula et al. (2011), Metcalf et al. (2010) and Pager et al. (2012). Metcalf et al. (2010) and Murray and Newton (2009) lacked details in terms of clear methods and process of analysis.

All empirical studies addressed ethical concerns. The qualitative studies provided more detail on the ethical issues than the quantitative studies, particularly concerning the methods of data gathering and the role of the researcher. Nine studies indicated financial support for their projects. No conflicts of interest were declared in any of the studies.

\section{Themes}

The four major themes captured the facilitators and barriers to health practitioners working collaboratively on research with academics and subsequently publishing their findings. These themes included practitioners, academics, institutions and professional demands. Numerical evidence of the studies associated with each of the themes is summarised in Table 3.

The quantitative distribution of the themes and subcategories allowed us to visualise the data and the relationship between the themes according to the frequency of identified codes (MAXQD11 software, 2015). The software indicated the percentage of codes related to each theme; the findings are shown in Figure 2. In the following sections, we have synthesised the four themes that emerged from the findings of the reviewed studies.

\section{Practitioners}

The term "practitioner" describes the health professional implementing care, such as nurses, medical staff or allied health professionals. This theme received the 
Table 3: Themes and sub-themes that emerged from reviewed studies.

\begin{tabular}{|c|c|c|c|}
\hline Themes & Subcategories & $\begin{array}{l}\text { No. of studies } \\
\text { per subcategory }\end{array}$ & Empirical sources \\
\hline \multirow[b]{2}{*}{ Practitioners } & $\begin{array}{l}\text { Interest / motiva- } \\
\text { tion and commit- } \\
\text { ment }\end{array}$ & 15 & $\begin{array}{l}\text { Bedoee, 2011; Behar-Horenstein and Johnson 2010; Dupin et al. 2015; Evans et al., } \\
\text { 2013; Finch et al., 2013, 2015; Gonzalez et al., 2012; Hauck et al., 2015; Jansen and } \\
\text { Hoeijmakers, 2013; Janssen et al., 2015; Metcalf et al., 2010; Pager et al., 2012; } \\
\text { Rickard et al.. 2011; Stephens et al., 2009; Ulrich et al., 2015. }\end{array}$ \\
\hline & $\begin{array}{l}\text { Competencies and } \\
\text { confidence }\end{array}$ & 17 & $\begin{array}{c}\text { Bedoee, 2011; Behar-Horenstein and Johnson, 2010; Evans et al.. 2013; Finch } \\
\text { et al., 2013, 2015; Gerrish et al., 2011; Gonzalez et al., 2012; Hauck et al., 2015; } \\
\text { Jansen and Hoeijmakers, 2013; Janssen et al., 2015; King et al., 2015; Metcalf et al., } \\
\text { 2010; Murray and Newton, 2009; Pager et al., 2012; Probst et al., 2015; Rickard et } \\
\text { al., 2011; Ulrich et al., 2015. }\end{array}$ \\
\hline \multirow{4}{*}{ Academics } & $\begin{array}{l}\text { Qualification and } \\
\text { collaboration }\end{array}$ & 9 & $\begin{array}{l}\text { Behar-Horenstein and Johnson, 2010; Dupin et al., 2015; Evans et al., 2013; Ger- } \\
\text { rish et al., 2011; Janssen et al., 2015; King et al., 2015; Koivula et al., 2011; Rickard } \\
\text { et al., 2011; Ulrich et al., 2015. }\end{array}$ \\
\hline & Mentoring & 8 & $\begin{array}{l}\text { Bedoee, 2011; Behar-Horenstein and Johnson, 2010; Evans et al.. 2013; Finch et } \\
\text { al., 2015: King et al., 2015; Probst et al., 2015; Rickard et al., 2011; Ulrich et al., } \\
\text { 2015. }\end{array}$ \\
\hline & Support & 14 & $\begin{array}{l}\text { Bedoee, 2011; Dupin et al. 2015; Evans et al., 2013; Finch et al., 2013, 2015; Gerrish } \\
\text { et al., 2011; Gonzalez et al., 2012; Hauck et al., 2015; Jansen and Hoeijmakers, } \\
\text { 2013; King et al., 2015; Metcalf et al., 2010; Pager et al., 2012; Probst et al., 2015; } \\
\text { Rickard et al., } 2011 .\end{array}$ \\
\hline & Feedback & 3 & Bedoee, 2011; Hauck et al., 2015; King et al., 2015. \\
\hline \multirow[b]{2}{*}{ Institutions } & $\begin{array}{l}\text { Educational institu- } \\
\text { tions }\end{array}$ & 5 & $\begin{array}{l}\text { Bedoee, 2011; Behar-Horenstein and Johnson 2010; Dupin et al. 2015; Metcalf et } \\
\text { al., 2010; Ulrich et al., } 2015 .\end{array}$ \\
\hline & Health institutions & 17 & $\begin{array}{l}\text { Bedoee, 2011; Behar-Horenstein and Johnson, 2010; Evans et al.. 2013; Finch et } \\
\text { al., 2015; Gerrish et al., 2011; Gonzalez et al., 2012; Hauck et al., 2015; Jansen and } \\
\text { Hoeijmakers, 2013; Janssen et al., 2015; King et al., 2015; Koivula et al. 2011; Met- } \\
\text { calf et al., 2010; Murray and Newton, 2009; Pager et al., 2012; Probst et al., 2015; } \\
\text { Rickard et al., 2011; Ulrich et al., 2015. }\end{array}$ \\
\hline \multirow{3}{*}{$\begin{array}{l}\text { Professional } \\
\text { demands }\end{array}$} & Culture & 6 & $\begin{array}{l}\text { Behar-Horenstein and Johnson, 2010; Dupin et al., 2015; Finch et al., 2015; Janssen } \\
\text { et al., 2015; Pager et al., 2012; Stephens et al., 2009. }\end{array}$ \\
\hline & Top-down & 3 & Metcalf et al., 2010; Murray and Newton, 2009; Ulrich et al., 2015. \\
\hline & Bottom-up & 3 & Bedoee, 2011; Jansen and Hoeijmakers, 2013; Metcalf et al., 2010. \\
\hline
\end{tabular}

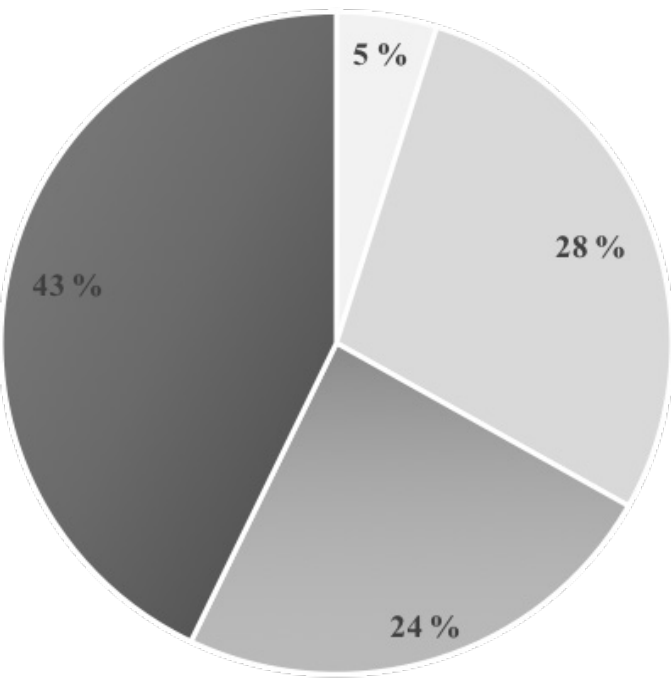

Professional demands

$\square$ Academics

Institutions

- Practitioners

Figure 2: Quantitative distinction of themes 
most attention in the reviewed studies. It focused on the practitioners' need to combine professional competencies with interest, motivation, commitment and confidence to perform research. Allied health professionals reported ambivalence about their involvement $(55 \%)$ and personal commitments as barriers to the undertaking of research (34\%), while $11 \%$ were not interested in this activity (Pager et al., 2012). Interestingly, while 50\% of these practitioners held undergraduate qualifications, they were not required to undertake research within their role in the health institution. Speech language pathologists reported an association between research interest and research engagement as well as variation in their level of research interest across different research tasks (Finch et al., 2013). Nurses indicated that researcher and nursing perspectives became more integrated as their interest in research grew through progression towards higher academic levels (Dupin et al., 2015). Similarly, participants described changes in the understanding of academic thinking and "working like a scientist" (Behar-Horenstein and Johnson, 2010, p. 64), as a basis for growing interest in doing research. In addition, those practitioners with no current involvement in research were the least interested in learning about research (Stephens et al., 2009). Nurses connected the level of research engagement with the lack of knowledge: "Definitely knowledge deficit... There are a lot of people that have done their nursing in hospitals, who don't have [the] academic background and that is a huge hurdle" (Evans et al., 2014, p. 228). Some social workers, professional leaders and managers considered research to be a "stretch" and preferred updating knowledge and skills at a more basic (non-research) level (Bedoee, 2011). Dupin et al. (2015) provided evidence that nurses' apprenticeships in research activities depended on the perceived usefulness in optimising patient care and direct connection to practice. These nurses focused on having separate research and nursing roles: "If I perform an interview and analyse a questionnaire, then I am a rresearcher, and $I$ feel very much as a researcher. For being a nurse, I see it more like being next to the patient" (Dupin et al., 2015, p. 76).

A lack of confidence amongst practitioners in their ability to conduct research emerged in 17 of the studies. The majority of public health professionals felt that their confidence to conduct research was low (Janssen et al., 2015). Furthermore, they expressed attitudes towards research directly related to their confidence and motivation for involvement in research activities. Participants who were not confident to participate in research also struggled to access electronic databases and to understand EBP. Similarly, $45 \%$ of nurses in Gerrish et al.'s (2011) research identified themselves as complete beginners or novices in relation to EBP skills. Amongst this group, $50 \%$ considered themselves competent or expert in relation to using EBP in their work. Only onequarter $(25 \%)$ of these nurses indicated that they felt competent to undertake research.

Overcoming low confidence and apprehension about the individual practitioner's ability to undertake research tasks successfully was a crucial element to subsequent engagement in research (Finch et al., 2015). Nurses in hospital-based research roles reported the need to have confidence in their pre-existing, in-depth knowledge in the associated clinical specialty before involvement in related research studies (Rickard et al., 2011). Further, nurses considered improvement in their critical appraisal skills to be crucial to overcome low levels of confidence and research engagement (Evans et al., 2014).

The most confident activity for $67 \%$ of therapeutic radiographers participating in Probst et al.'s (2015) research was the use of quantitative methods. Regarding research type, physiotherapists preferred randomised controlled trials and systematic reviews; they perceived case studies or case series as less scientific, while qualitative research methods were not mentioned (Janssen et al., 2015). Nurses also stressed the value of syntheses of research in the form of systematic reviews and indicated greatest confidence, experience and interest in qualitative research methods (Gerrish et al., 2011).

Lack of confidence connected with lack of research competencies, skills and knowledge to undertake research occurred in six studies. Allied health professionals (54\%) reported the lack of research skills and knowledge as one of their main barriers to research (Pager et al., 2012). Practitioners in studies by Evans et al. (2014), Hauck et al. (2015) and Murray and Newton (2009) emphasised that research knowledge and skills increased only after further education provision on top of their undergraduate studies. Furthermore, traditional Masters programmes may provide insufficient research training while higher doctoral research training, Masters by Research and/ or Master of Philosophy qualifications were reported as most appropriate for developing applicable research skills (Probst et al., 2015). For example, public health professionals valued confidence in performing oral presentations and increased the ability to contact university staff to collaborate in new research projects following "master class" research-related programmes (Jansen and Hoeijmakers, 2013). These health professionals $(31 \%)$ felt confident to analyse data from new research without supervision, while $25 \%$ reported low confidence in following medical ethics approval procedures. Conversely, students majoring in different sciences reported gains in various research skills while undertaking one specific undergraduate course (BeharHorenstein and Johnson, 2010). An alternative way of learning knowledge and skills was expressed by nurses in research roles within one hospital who indicated 
"learning on the job" (Rickard et al., 2011, p. 172) was central to their development. These nurses explained that some practitioners preferred to learn informally rather than through formal postgraduate studies (Rickard et al., 2011).

Participants' abilities to write for professional publication indicated developing research competencies in seven studies (as summarised in Table 3). These studies commonly reported a link between a participant's desire to develop skills and increase knowledge with successful publishing or presenting results of research activities. For example, a desire to prove a theory or hunch, undertake and publish research for career advancement, recognition and job satisfaction was reported (Pager et al., 2012). However, respondents frequently considered themselves inexperienced or lacking confidence when applying for research funding, writing and presenting oral reports or writing for publication (Finch et al., 2013; Stephens et al., 2009). One-quarter of allied health professionals reported feeling intimidated by research language (Pager et al., 2012). Public health professionals (25\%) also reported low confidence in writing scientific articles in English (Jansen and Hoeijmakers, 2013). Similarly, physiotherapists indicated a lack of confidence in their writing ability with comments such as "writing is not for me" and "[writing is] a very highfaluting [high status] kind of activity" (Murray and Newton, 2009, p. 31). Lack of writing confidence also emerged as a moderate or major barrier to research-related publications in $50 \%$ of respondents in King et al.'s (2015) study. Low confidence was one of the two most powerful barriers to writing, together with "difficulty in getting started" (King et al., 2015, p. 180). Overall, participants indicated the need for developing research competencies, increased academic vocabulary, greater guidance and support, as well as further practical experience in the field before embarking on research as ways of developing greater confidence (Bedoee, 2011; King et al., 2015).

\section{Academics}

The term "academic" describes those employed in universities undertaking either teaching or research or a combination of these activities. The importance of mentoring, ongoing support, feedback, qualifications and collaboration emerged as expectations of academics across all the reviewed studies. Feedback, support and mentoring figured as the most important of the academics' contributions to the shared academic/ practitioner publishing effort. Moreover, individual academic qualifications, as well as the level of established collaborations with practitioners, influenced the outcome of these individual-based research activities.
Personal characteristics including interest, motivation and commitment that academics manifested indirectly related to their demographic characteristics, an interesting aspect that has remained relatively unexplored. However, participants' academic degrees and official titles showed significant connections to their broad approaches to knowledge acquisition (Koivula et al., 2011). More specifically, academics considered $\mathrm{PhD}$ acquisition to be a necessity to their research education and acculturation (Dupin et al., 2015).

Koivula et al. (2011) found that $40 \%$ of academic participants undertook no research activities. In addition, these academics provided significantly less nursing science-based teaching and had a narrower knowledge acquisition and a more traditional approach to teaching than those working in research and development. Furthermore, most of these nursing academics held Master's degree qualifications, although $12 \%$ had "a licentiate" or PhD (Koivula et al., 2011). Unsurprisingly, only $12 \%$ of these participants had published in international, peer-reviewed scientific journals, while $30 \%$ had conference-based publications. At the same time, radiologic technologists holding doctoral degrees reported lack of specific training and mentorship in how to write for publication during their doctoral programmes as well as when they entered the workplace (Metcalf et al., 2010). Controversially, 30 research radiographers participating in Probst et al.'s (2015) study reported 27 peer-reviewed articles published and 95 conference presentations delivered in the period of 12 months. All held higher degree (postgraduate) qualifications, three had $\mathrm{PhDs}$, while two were professors. Interestingly, these participants reported that very little time $(<10 \%)$ was devoted to writing research proposals or publications, while partnerships and collaborations were not developed (Probst et al., 2015). Yet, medical staff, non-medical practitioners and administrative staff indicated that developing and sustaining research collaborations were crucial; they highlighted that issues connected to the lack of communication and collaboration between researchers, practitioners and users, while responsibility for this cooperation was placed on academics (Gonzalez et al., 2012).

Academic and/or health professional researchers who chose to participate in clinical activities through the provision of support and mentoring emerged as the most valued (Gonzalez et al., 2012; Ulrich et al., 2015). In particular, over $90 \%$ of nurse scientists indicated that three issues underpinned successful research collaborations: clearly defined roles, responsibilities and boundaries; clear and frequent communication and complementary interests or expertise (Ulrich et al., 2015). Surprisingly, in this digital age, these participants 
also reported close geographic proximity of collaborators as important to their successful collaborations. Lack of communication $(92.1 \%)$ and timeliness $(90.9 \%)$ emerged as challenging to successful research partnerships. Most of these respondents reported learning about collaborative relationships from personal experiences and from research mentors (Ulrich et al., 2015). Mentoring, feedback and ongoing support arose as strong sub-themes across reviewed studies. Interestingly, only BeharHorenstein and Johnson (2010) criticised academics for failing to engage with practitioners when providing research-related presentations. Mentoring was regarded as a central and essential component empowering practitioners' research experiences and emerged as the most significant facilitating factor in practitioners' involvement in research. For example, allied health professionals (41\%) acknowledged mentors as personal motivators and enablers (Pager et al., 2012). Even with increased publication outputs after a "writing for publication" course, physiotherapists identified the need for further mentoring and ongoing support (Murray and Newton, 2009). King et al. (2015) investigated the role of mentors further: their respondents $(>80 \%)$ appreciated encouraging supervisor and peer feedback. Positive comments on drafts and suggestions of worthiness for publication assisted participants to progress towards subsequent journal submission and successful publication, even if they had published previously (King et al., 2015).

\section{Institutions}

The term "institution" refers to an employing organisation involved in research, education and/or health care. Institutional characteristics of educational and health institutions, such as organisation, orientation and operationalisation of activities, were recognised as crucial in facilitating or obstructing research activities in 18 studies. Time, pressures of practical work and leadership were major issues for involvement in research across participants, groups and studies, conducted in both educational and health institutions. These factors reflected those traditionally cited in the literature: conflicting job demands and a heavy workload, lack of time for research, other work roles taking priority, low staffing levels and high staff turnover (Bedoee, 2011; Behar-Horenstein and Johnson, 2010; Pager et al, 2012).

Lack of resources especially funding and/or discrepancies in the ways in which different practitioners' disciplines received resource provision emerged. The lack of coordination of approaches, due to little support given by managers, was noticeable (Pager et al, 2012). Limited infrastructure such as access to computers, research-specific software and dedicated workspaces and administrative support were also problematic (Metcalf et al., 2010). In addition, becoming a researcher was regarded as difficult due to the lack of clear career pathways (Rickard et al., 2011) and balancing research activities with family life (Metcalf et al., 2010). Furthermore, linking research to business planning cycles, job recruitment and advertising materials and/or nominating employees as leaders of research teams within departments varied widely. The variations indicated great differences in the priority of research within educational and health institutions' organisational structures and processes (Probst et al., 2015; Ulrich et al., 2015). The opportunity to research together as a team, led by a supportive team manager, was also an important enabler (Pager et al., 2012; Rickard et al., 2011). Similarly, Dupin et al.'s (2015) findings revealed a causal link between practitioners' research learning processes and activities, facilitated by established integration which drew them into academic structures, peer groups and exchanges with other students.

Interestingly, characteristics of educational institutions including organisation, orientation and operationalisation of activities accompanied by their endeavour to cooperate with health institutions to undertake research appeared unexplored. The organisation of specific research programmes or courses on offer emerged as important in five of the studies. Specifically, access to university facilities and well-coordinated, relevant and structured courses along with effective supervision contributed strongly to the development of practitioners' research knowledge (Bedoee, 2011; Behar-Horenstein and Johnson, 2010; Dupin et al., 2015; Metcalf et al., 2010; Ulrich et al., 2015). In addition, these studies identified the achievement of creative linkages between universities and health institutions as extremely important. These authors proposed introducing apprenticeship arrangements including research traineeships, training fellowships, postdoctoral career opportunities and affiliations with universities and university-based researchers for health professionals. The studies noted that health institutions needed to invest in workforce development and research infrastructure to assist in the research education of their staff (Bedoee, 2011; Behar-Horenstein and Johnson, 2010; Dupin et al., 2015; Metcalf et al., 2010; Ulrich et al., 2015).

Relationships between the academic and health institutions were challenging for nurse "scientists" (Ulrich et al., 2015), particularly for multidisciplinary and international collaborations across different academic and practice settings. Laboratory and clinically based research especially challenged multidisciplinary collaboration. The expanded use of qualitative methodologies and mixed methods led to greater requirements of qualitative expertise in many research teams. Participants reported that negotiating their role in a well-established quantitative research group brought epistemological 
challenges in relation to data ownership (Ulrich et al., 2015). Moreover, nurse respondents $(54.5 \%)$ in Ulrich et al.'s (2015) sample agreed that junior faculty academics were at risk of being exploited in these collaborative relationships. Studies involving participants from other professions have not illuminated these issues.

\section{Professional demands}

The term "professional demand" refers to expectations and requirements of professionals in the course of their employment. Professional demands as well as those required by governments and/or governmental bodies through hierarchical based policies received substantially less attention. These demands placed on both academics and practitioners emerged in 11 studies, as summarised in Table 3. The specific professional discipline and its existing culture were noted to have an effect (facilitating or obstructing) on practitioners' and academics' approaches and knowledge of research.

Several physiotherapists emphasised that their discipline's culture and expectation had shaped their motivation towards involvement in research, increasing their professional status "research buys us that academic title, and also it should cement our position within the healthcare system" (Janssen et al., 2015, p. 4). In contrast, another participant's view was "we're now legally bound to work within evidence-based practice and there's no such real thing. In the majority of our physiotherapy, realistically... you can't measure it, you can't research it" (Janssen et al., 2015, p. 4). Social workers viewed research as a way of justifying their actions and roles in institutions. Research findings "help us to better meet the managerial demands [for] effectiveness, we can more effectively answer what it is that social work brings to this organization, what it brings to its clients... in a way that impresses other people" (Bedoee, 2011, p. 563). A further social worker stated that their development in research "would be seen in terms of paralleling other professions, particularly doctors a kudos thing really" (Bedoee, 2011, p. 569). Similarly, in Dupin et al.'s (2015) study, hospital nurse researchers' perspectives on research merged with their professional identity. One participant perceived being a researcher as "something you breathe, to be a researcher, is to breathe new knowledge" (Dupin et al., 2015 , p. 76). Nurses identified a form of loneliness as a barrier and pointed to the need to defend research as an essential component of the nursing profession. Allied health professionals also reported feelings of isolation because of little support from managers as well as from colleagues and partners (Pager et al., 2012). This notable variation in cultural expectation around research activity echoed across disciplines. Speech therapists expressed the highest level of research interest, followed by social workers, occupational therapists and physical therapists with dieticians indicating no interest or experience in research at all (Stephens et al., 2009).

Changing the prevailing culture towards research within their disciplines was, according to participants, essential to encourage greater participation in and engagement with research by others. For example, participants in Bedoee's (2011) study described basing their work on research evidence as a vital element of professional culture. Similarly, Dupin et al. (2015) depicted learning about research as a continual process of creating new knowledge and professional development. Professional communities that supported members' research qualification development appeared to be a major facilitator in the development of nurse researchers. Participants described sharing research practices and projects as a way of contributing to knowledge development and developing collaborations across academia, clinical practice and management (Dupin et al., 2015).

However, several studies emphasised the ethical need to provide better evidence of the effectiveness and impact of practitioners' work. These authors recommended longitudinal research to evaluate the impact of research evidence application to health professionals' practice along with the need to increase interest and passion for research amongst practitioners in general. Yet, the demands placed on practitioners in the current professional environment have rarely received attention in recent studies. Strategic initiatives intended to increase the level of research engagement amongst health practitioners emerged: "health professionals' competency assurances have taken on a whole new meaning around people's continuing education... ensuring that they are keeping up to date with latest trends...." (Bedoee, 2011, p. 564). Participants in Pager et al.'s (2012) study reported a new health initiative driving the research agenda as a significant motivator for their involvement in research. Furthermore, an appreciation of value driven personcentred or participatory approaches to social and health research emerged in studies by Bedoee, (2011), Dupin et al. (2015) and Gerrish et al. (2011) studies, where participants focused strongly on client satisfaction and working collaboratively with service users.

\section{DISCUSSION}

Despite the heterogeneity of the practitioners and academics participating in the reviewed studies, our synthesis of the evidence resulted in themes that were found to be interrelated. The relationship between practitioners, academics, professional demands, health organisations and educational organisations emerged as critical to successful collaboration in research activities and dissemination of findings through publication (Figure 3). 


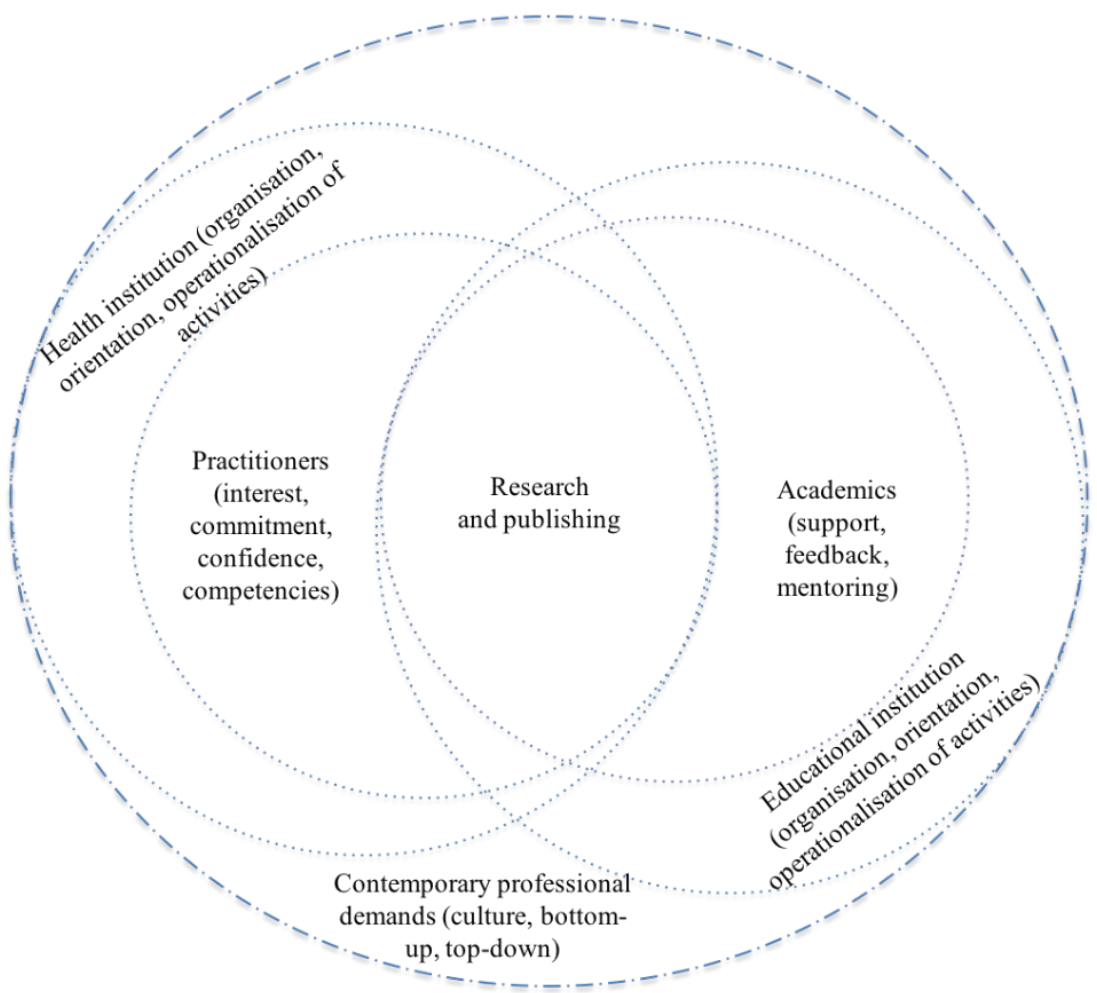

Figure 3: The relationship between practitioners, academics, professional demands and employing organisations and their impact on collaborative research activities

Barriers were also found that reduced collaborative research activities between practitioners and academics in nursing as well as the other disciplines (Janssen et al., 2015; Hauck et al., 2015). Practitioners particularly reported a lack of research knowledge, skills and confidence and the need for ongoing development. The importance of user participation received powerful support in the literature (Carr, 2007, Markauskaite and Goodyear, 2014; Read and Maslin-Prothero, 2011; Truman and Raine, 2001).

Practitioners' need for ongoing support from academics was highlighted. On the other hand, academics identified their need to gain further research education and a higher level of qualification such as $\mathrm{PhD}$ (Logan et al. 2015). Surprisingly, however, less emphasis was placed on the importance of academics' interest and motivation towards research and capacity to link with practitioners. Likewise, limited attention was directed towards the accountability of academics and their commitment to mentoring, feedback and ongoing support. However, specific challenges emerged for nursing academics seeking national and international multidisciplinary collaborations with other academics and practitioners. Despite potential issues, conducting research in groups allowed, amongst other things, collaboration between a range of individuals, environments and cultures across disciplines (Griffin et al., 2005).

The academics' qualifications, further education, research and publication activities affected their ability to mentor practitioners in collaborative research and publication endeavours.

The importance of academics and practitioners bridging the theory-practice gap through professional education has been a major focus in the literature (Benner et al., 2010; Sullivan, 2005). However, bridging the researchtheory-practice gap has received far less attention in the literature. The research-theory-practice nexus has major implications for the development of evidence to inform the practical and theoretical knowledge of the discipline. The findings also indicated that academics and practitioners have been isolated in their research activities in a number of disciplines. While the research capacity of nursing internationally has increased largely because of extensive use of qualitative methodologies, such activities may be unsupported by employing institutions from their own and other disciplines (Hoff and Witt, 2000; Show, 2003; Weiner et al., 2011).

The facilitators and barriers that emerged from the reviewed studies establish the relationship of an individual's personal and professional characteristics 
(such as motivation, interest and academic qualification) and their subsequent research activities. However, the importance of the academics' and practitioners' research activities reached beyond the personal and professional characteristics of these individuals. To make it possible for academics and practitioners to overcome these barriers, cooperative and collective actions are necessary. Siedlecki et al. (2017), investigating research active nurses, highlighted the need for research-supportive environments and mentor support. In contrast, weak relationships hindered the development and undertaking of collaborative research activities, especially in relation to educational institutions. Therefore, health and educational institutions and professional communities need to encourage the building of collaborative, collegial networks. These networks need to extend across their own disciplines and beyond, thereby disseminating and creating new interdisciplinary knowledge.

Existing dissonance in conceptual understanding and structural support influenced whether research activities developed across institutions or remained fragmented, individualised and isolated. Likewise, relationships between academics and practitioners, within and across organisations, were crucial to collaborative research activities.

Interestingly, none of the reviewed studies stated the professional associations' positions on practitioners' involvement in research. Yet, professional associations support practitioners to participate and adopt EBP to provide best clinical practice (Hordern, 2014). These associations have been particularly vocal in stipulating the maintenance of high standards of professional practice and in negotiating and setting professional and institutional norms (Nerland and Karseth, 2013). As Sackett (1996) asserted, to achieve the objectives of EBP, both professional and organisational development must occur.

The findings also pointed out that the existing levels of collaboration relied on individuals. Despite the final "product" for both professional education and health system delivery being the best quality of health care possible with regard to patient outcomes, well-established links between educational and health institutions were not found. Current requirements for assuring safety and quality in the delivery of health care services (AHCS, 2012) require practice and educational collaboration. Quality assurance and accountability are needed within educational systems (Frank et al, 2012; Higher Education Standards Framework [Threshold Standards], 2015) and professional standards (Abbott, 1988; Friedson, 2001) particularly in relation to nurse and other health practitioners (Benner et al., 2009; McGee and Castledine, 2003; Sullivan, 2005). This relationship can only occur where the previously mentioned tensions that influence professional knowledge building and transformation are not present. It also highlights the necessity for strong institutional collaboration, for common actions to establish shared preconditions to secure safety and quality in the delivery of services, by providing opportunities for practitioners and academics to continually expand and improve their research capabilities. Furthermore, drawing together academics and practitioners in the development of practice through research activities and publication of research is, in response to twenty-first century requirements, a critical necessity.

\section{Strengths and Limitations}

This literature review was limited by the number of available and relevant empirical studies. While search terms were chosen carefully, some studies with relevant content may have been missed due to variation in key terms used. The search was also limited to studies published in English potentially omitting pertinent studies published in other languages. Reviewers minimised reporting bias through the use of cross-checking and reflection on decision-making by the authorship team.

The majority of these studies provided limited information on research designs, research questions, data gathering processes and analyses. While the studies in this review suggest that nursing holds a prominent position in undertaking research activities compared with other health professionals (excluding medicine) and social workers (Bedoee, 2011; Janssen et al., 2015), it may be problematic to draw conclusions about individual professions. Generalisation of findings requires a cautious approach when applied to individual professions as studies may describe local practice only, particularly in relation to professions with low representation in respondent numbers. For example, the reported dietician disinterest in research from a single study provides little grounds for generalisation. However, the value of this systematic review lies in the consideration of overall themes and related strategies that can apply across professions. While interdisciplinary and contextual differences are acknowledged, there appears to be a high level of similarity in the findings and therefore potential transferability across disciplines.

\section{CONCLUSIONS AND POTENTIAL IMPLICATIONS}

There is a lack of substantial research on the issue of practitioner-academic researcher collaboration as the available literature reaffirms the established academic-centric practice. Therefore, an important finding arising from this review is the limited amount of research examining the practitioner perspective on how to generate and disseminate clinical research and 
knowledge. There is a need for educational institutions to promote continuing cooperation with the health care sector and ongoing opportunities and encouragement for research development and collaborative research activities. Likewise, the health sector must recognise the need for investment in workforce development by operationalising the development of appropriate research infrastructure. A move is necessary towards a greater role of research rather than the prevailing efficiency and productivity measures as the only foci of health services (Hollingsworth, 2008).

One possibility would be to establish strong inclusive collaborative research centres that seek to maintain continuous development of research abilities and ongoing support for academics and practitioners. Currently, collaborative research centres often tend to focus successfully on high-end medical-related research. However, there is a need to address interdisciplinary practice and implementation of best evidence by involving larger numbers of practitioners. Step-by-step high-quality robust guidance in research and publishing processes for academics and practitioners regardless of their professional background would hasten the progress. Professional associations must take proactive action to create pathways and processes of knowledge appropriation and transformation for professional practice. These associations are in an excellent position to actively encourage the research and publishing activities of their members through funding opportunities and showcasing new evidence for practice.

Finally, in conclusion, we emphasise that it is increasingly difficult for a single individual (health practitioner or academic) to endeavour to undertake research activities in the current climate of the health care and educational systems. Working and learning together through intra-disciplinary, interdisciplinary and international collaborations, we see as central to securing innovations, developing and transforming knowledge, professional advancement and creative learning as well as quality in the delivery of services. Ultimately, we argue for research, education and practice integration through organised and structured cooperation in and across educational and health care institutions.

\section{References}

Abbott, A., 1988. The System of Professions. An essay on the division of labor. The University of Chicago Press, Chicago.

Australian Council on Healthcare Standards (ACHS), 2012. EQuIP National Standards. Australian Council on Healthcare Standards, Sydney.

Bedoee, L., 2011. Investing in the Future: Social workers talk about research. Br. J. Soc. Work, 41, 557-575. http://dx.doi.org/10.1093/ bjsw/bcq138.

Behar-Horenstein, L., Johnson, M.L., 2010. Enticing Students to Enter into Undergraduate Research: The instrumentality of an undergraduate course. J. Coll. Sci. Teach. 39 (3), 62-70. http:// search.proquest.com/openview/c7a80a16033fea9222cc4844d $1 \mathrm{fef32e} / 1$ ?pq- origsite $=$ gscholar $\& \mathrm{cbl}=49226$ (accessed on 14 December, 2016)

Benner, P., Sutphen, M., Leonard, V., Day, L., 2009. Educating nurses: A call for radical transformation (vol.1). Jossey-Bass, CA.

Bereiter, C., Scardamalia, M., 1993. Surpassing ourselves: an inquiry into the nature and implications of expertise. Open Court Publishing Compan, Chicago Ill.

Brunton, G., Stansfield, C., Thomas, J., 2012. Finding relevant studies, in Gough, D., Oliver, S., Thomas, J. (Eds.), An introduction to systematic reviews. Sage, London, pp. 107-135.

Carr, S., 2007. Participation, power, conflict and change: Theorizing dynamics of service user participation in the social care system of England and Wales. Critical Social Policy. 27 (2), 266- 276. http:// dx.doi.org/10.1177/0261018306075717.

Dupin, C. M., Larsson, M., Dariel, O., Deboit, C., Rothan-Tondeur, M., 2015. Conceptions of learning research: Variations amongst French and Swedish nurses. A phenomenographic study. Nurse Educ. Today, 35, 73-79. http://dx.doi.org/10.1016/j.nedt.2014.06.003.

Engeström, Y., 2008. From teams to knots: Activity-theoretical studies of collaboration and learning at work. Cambridge University Press, Cambridge. http://dx.doi.org/10.1017/cbo9780511619847.

Eraut, M., 1985. Knowledge creation and knowledge use in professional contexts. Studies in Higher Education. 10 (2), 117-133. http:// dx.doi.org/10.1080/03075078512331378549.

Eraut, M., 1994. Developing Professional Knowledge and Competence. Routledge Falmer, NY. http://dx.doi.org/10.4324/9780203486016.

Evans, G., Duggan, R., Boldy, D., 2014. An exploration of nursing research perceptions of registered nurses engaging in research activities at metropolitan hospital in Western Australia. Collegian. 21, 225- 232. http://dx.doi.org/10.1016/j.colegn.2013.04.006.

Finch, E., Cornwell, P., Nalder, E., Ward, E., 2015. Uncovering motivators and stumbling blocks: Exploring the clinical research experiences of speech-language pathologists. Int. J. Speech Lang. Pathol. 17 (2), 138-147. http://dx.doi.org/10.3109/17549507.2014 .930175 .

Finch, E., Cornwell, P., Ward, E. C., McPhall, S.M., 2013. Factors influencing research engagement: research interest, confidence and experience in an Australian speech-language pathology workforce. BMC Health Serv. Res.13 (144), DOI: 10.1186/1472-6963-13-144.

Frank, A., Kurth, D., Mironowicz, I., 2012. Accreditation and quality assurance for professional degree programmes: comparing approaches in three European countries. Quality in Higher Education. 18 (1), 75-95. http://dx.doi.org/10.1080/13538322.201 2.669910 . 
Freidson, E., 2001. Professionalism. The Third Logic. Polity, Cambridge.

Gerrish, K., Guillaume, L., Kirshbaum, M., McDonnell, A., Tod, A., Nolan, M., 2011. Factors influencing the contribution of advanced practice nurses to promoting evidence-based practice among front-line nurses: findings from a cross-sectional survey. J. Adv. Nurs. 67 (5), 1079-1090. http://dx.doi.org/10.1111/j.13652648.2010.05560.x.

Gonzalez, J.M., Cortes, D.E., Reeves, T., Whitley, R., Lopez, L., Bond, G. R., Miller, A.L., 2012. Community Mental Health Agency Views of Research. Community Ment. Health J. (48), 223-

231. http://dx.doi.org/10.1007/s10597-011-9397-6.

Gough, D., Oliver, S., Thomas, J., 2012. Introducing systematic review, in Gough, D., Oliver, S. and Thomas, J. (Eds.), An introduction to systematic reviews. Sage, London, pp.1-17.

Griffin, G., Green, T., Medhurst, P., 2005. The relationship between the process of professionalization in academe and interdisciplinarity: A comparative study of eight European countries. University of Hull Kingston upon Hull, UK:. http://www.hull.ac.uk/ researchintegration/Comparative \%20Report \%20-\%20 Profesionalization\%20and\%20Interdisciplinarity.pdf (access 14 December, 2016).

Grimen, H., 2008. Profesjon og kunnskap [Profession and knowledge], in Molander, I. and Terum, L. (Eds.), Profesjonstudier [The study of profession] Universitesforlaget, Oslo, pp.71-87.

Hauck, Y. L., Lewis, L., Bayes, S., Keyes, L., 2015. Research capacity building in midwifery: Case study of an Australian Graduate Midwifery Research Intern Programme. Women and Birth. (28), 259-263. http://dx.doi.org/10.1016/j.wombi.2015.02.005.

Higher Education Standards Framework (Threshold Standards), 2015. Commonwealth of Australia: Federal Register of Legislative Instruments (F2015L01639). https://www.legislation.gov.au/ Details/F2015L01639 (accessed 14 December 2016).

Hollingsworth, B., 2008. The measurement of efficiency and productivity of health care delivery. Health Economics. 17, 11071128. http://dx.doi.org/10.1002/hec.1391.

Hinshaw, A.S.A., 2001. Continuing Challenge: The shortage of educationally prepared nursing faculty. Online J. Issues Nurs. 6 (1), 1-9. www.ncbi.nlm.nih.gov/pubmed/11382330 (accessed 14 December, 2016).

Hoff, T.J., Witt, L.C. 2000. Exploring the Use of Qualitative Methods in Published Health Services and Management Research. Medical Care Research Review. 57 (2), 139-160. http://dx.doi. org/10.1177/107755870005700201.

Hordern, J., 2014. Productive Systems of Professional Formation, in Billettet, S., Harteis, C. and Gruber, H. (Eds.), International Handbook of Research in Professional and Practice-based Learning, Springer International Handbooks of Education, DOI 10.1007/978-94-017-8902-8.

Jansen. M.W.J., Hoeijmakers, M., 2013. A Masterclass to Teach Public Health Professionals to Conduct Practice-Based Research to Promote Evidence-Based Practice: A case study from the Netherlands. J. Public Health Manag. Pract, 19 (1), 83-92. http:// dx.doi.org/10.1097/PHH.0b013e318225158a.
Janssen, J., Hale, L., Mirfin-Veitch, B., Harland, T., 2015. Perceptions of physiotherapists towards research: A mixed methods study. Physiotherapy. 102 (2), 210-216. http://dx.doi.org/10.1016/j. physio.2015.04.007.

King L, Gilham D \& Crotty M (2017) Facilitating publication by clinicians who are postgraduate students: using research to inform subject design. GSTF Journal of Nursing and Health Care. December;5:1 <Accessed July 20, 2018> http://dl6.globalstf. org/index.php/jnhc/article/view/1304. doi: 10.5176/2345718X_5.1.176

King, L., Crotty M., Gillham, D., 2015. Facilitating refereed publication by health professionals: research informed software to scaffold the integration of research evidence with practice knowledge. 38th HERDSA Annual International Conference. Melbourne, Australia. Research and Development in Higher Education: Learning for Life and Work in a Complex World, 38, 176-185. <Accessed 14 December, 2016>. http://herdsa.org.au/publications/conferenceproceedings/research-and-development-higher-education-vol-38.

Koivula, M., Tarkka, M-T., Simonen, M., Katajisto, L., Salminen, L., 2011. Research utilisation among nursing teachers in Finland: A national survey. Nurse Educ. Today. 31, 24-30. http://dx.doi. org/10.1016/j.nedt.2010.03.008.

Logan, P.A., Gallimore, D., Jordan, S., 2015. Transition from clinician to academic: an interview study of the experiences of UK and Australian Registered Nurses. J. Adv. Nurs. 72 (3), 593-604. http:// dx.doi.org/10.1111/jan.12848.

Long, A.F., Godfrey, M., Randall, T., Brettle, A. J., Grant, M.J., 2002. Developing Evidence Based Social Care Policy and Practice. (Part 3). Feasibility of Undertaking Systematic Reviews in Social Care (Project Report). Leeds UK: Nuffield Institute for Health, University of Leeds. http://usir.salford.ac.uk/13071/1/ Long_et_al_2002_Feasibility_Social_Care_Review_-_part_III.pdf (accessed 14 December 2016).

Markauskaite L., Goodyear P., 2014. Professional Work and Knowledge, in Billett, S., Harteis, C.and Gruber, H. (Eds.) International Handbook of Research in Professional and Practicebased Learning, Springer International Handbooks of Education. http://dx.doi.org/10.1007/978-94-017-8902-8_4.

MAXQDA 11 [Computer software], 2015. Retrieved from www. maxqda.com/

McGee, P., Castledine, G., 2003. Advanced Practice, second ed. Blackwell Science, Oxford.

Metcalf, K.L., Adams, R.D., Qaqish, B., Church, J.A., 2010. Surveys of R.T`s with doctorates: Barriers to conducting research. Radiol. Technol., 81 (5),417-427. http://www.radiologictechnology.org/ content/81/5/417.long8 (accessed 14 December, 2016).

Moher, D., Liberati, A., Tetzlaff, J., Altman, D. G. The PRISMA Group, 2009. Preferred Reporting Items for Systematic Reviews and Meta-Analyses: The PRISMA Statement. PLoS Med. 6 (6): e1000097. http://dx.doi:10.1371/journal.pmed1000097.

Murray, R., Newton, M., 2009. Facilitating writing for publication. Physiotherapy. 94, 29-34. http://dx.doi.org/10.1016/j. physio.2007.06.004. 
Nerland, M., Karseth, B., 2013. The knowledge work of professional associations: Approaches to standardisation and forms of legitimisation. Journal of Education and Work. http://dx.doi.org/10 $.1080 / 13639080.2013 .802833$.

Oliver, S., Sutcliffe, K., 2012. Describing and analysing studies, in Gough, D., Oliver, S. and Thomas, J. (Eds.), An introduction to systematic reviews. Sage, London, pp.135-153.

Pager, S., Holden, L., Golenko, X., 2012. Motivators, enablers, and barriers to building allied health research capacity. J. Multidiscip. Healthcare. (5), 53-59. http://dx.doi.org/10.2147/JMDH.S27638.

Pawson, R., Boaz, A., Grayson, L., Long, A., Barnes, C., 2003. Types and quality of knowledge in social care. Social Care Institute for Excellence, London. https://www.scie.org.uk/publications/ knowledgereviews/kr03.pdf (accessed 14 December, 2016).

Probst, H., Harris, R., McNair, H.A., Baker, A., Miles, E.A., Beardmore, C., 2015. Research from therapeutic radiographers: An audit of research capacity within the UK. Radiography. (21), 112-118. http://dx.doi.org/10.1016/j.radi.2014.10.009.

Read, S., Maslin-Prothero, S., 2011. The Involvement of Users and Carers in Health and Social Research: The realities of inclusion and engagement. Qual. Health Res. 21 (5), 704-713. http://dx.doi. org/10.1177/1049732310391273.

Rickard, C.M., Williams, G., Ray-Barruel, G., Armit, L., Perry, J.C., Luke, P., Wallis, M., 2011. Towards improved organisational support for nurses working in research roles in the clinical setting: A mixed method investigation. Collegian.18, 165-176. http:// dx.doi.org/10.1016/j.colegn.2011.07.002.

Sackett, D., 1996. Evidence-based medicine: what it is and what it isn't. BMJ. 13;312 (7023),71-2. http://dx.doi.org/10.1136/ bmj.312.7023.71.

Siedlecki, S.L., Albert, N.M., 2017. Research active clinical nurses: against all odds. Journal of Clinical Nursing.

Show, I., 2003. Qualitative research and outcomes in health, social work and education. Qualitative Research, 3 (1), 57-77. http:// dx.doi.org/10.1177/146879410300300103.

Staykova, M.P., 2012. A pilot Delphi study: Competencies of nurse educators in curriculum design. Teaching and learning in Nursing, 7, 113-117. http://dx.doi.org/10.1016/j.teln.2012.01.006.

Stephens, D., Taylor, N., Leggat, S.G., 2009. Research Experience and Research Interests of Allied Health Professionals. J. Allied Health. 38 (4), 107-111. www.ncbi.nlm.nih.gov/pubmed/20011811.

Sullivan, W.M., 2005. Work and integrity: The crisis and promises of professionalism in America, second ed. Jossey-Bass, San Francisco, pp. 1-33

Thomas, J., Harden, A., Newman, M., 2012. Synthesis: Combining results systematically and appropriately, in Gough. D., Oliver, S. and Thomas, J. (Eds.), An introduction to systematic reviews. Sage, London, pp.179-227.

Truman, C., Raine, P., 2001. Involving users in evaluation: the social relations of user participation in health research. Crit. Public Health. 11 (3), 215-229. http://dx.doi.org/10.1080/09581590110066667.
Ulrich, C.M., Wallen, G.R., Cui, N., Chittams, J., Sweet, M., Plemmons, D., 2015.Establishing good collaborative research practices in the responsible conduct of research in nursing science. Nurs. Outlook. (63), 171-180. http://dx.doi.org/10.1016/j.outlook.2014.10.007.

Weiner, B.J., Amick, H.R., Lund, J.L., Lee, S-Y.D., Hoff, T.J., 2011. Use of Qualitative Methods in Published Health Services and Management Research: A 10-year review. Medical Care Research Review. 68 (1), 3-33. http://dx.doi. org/10.1177/1077558710372810. 


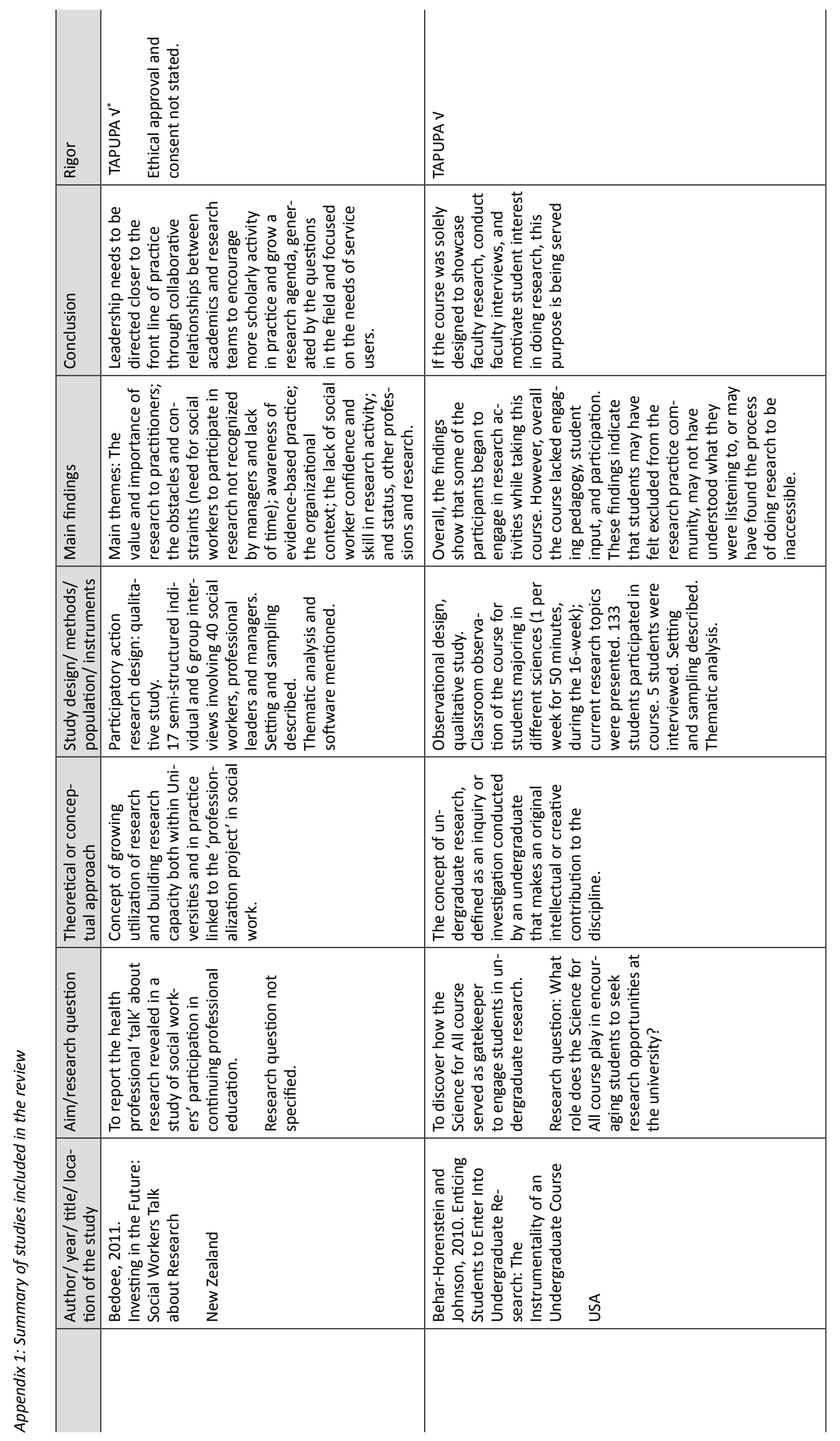




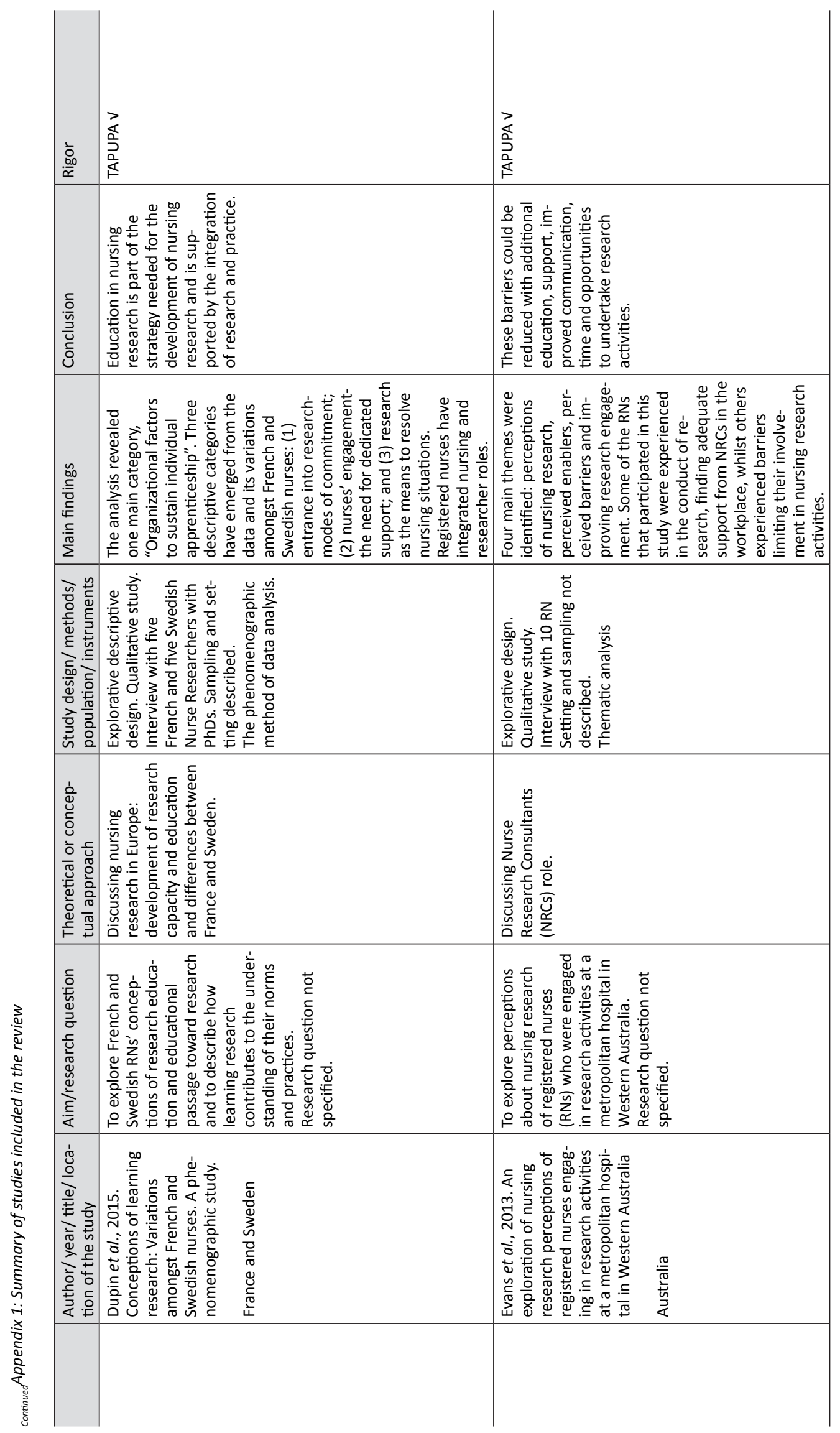




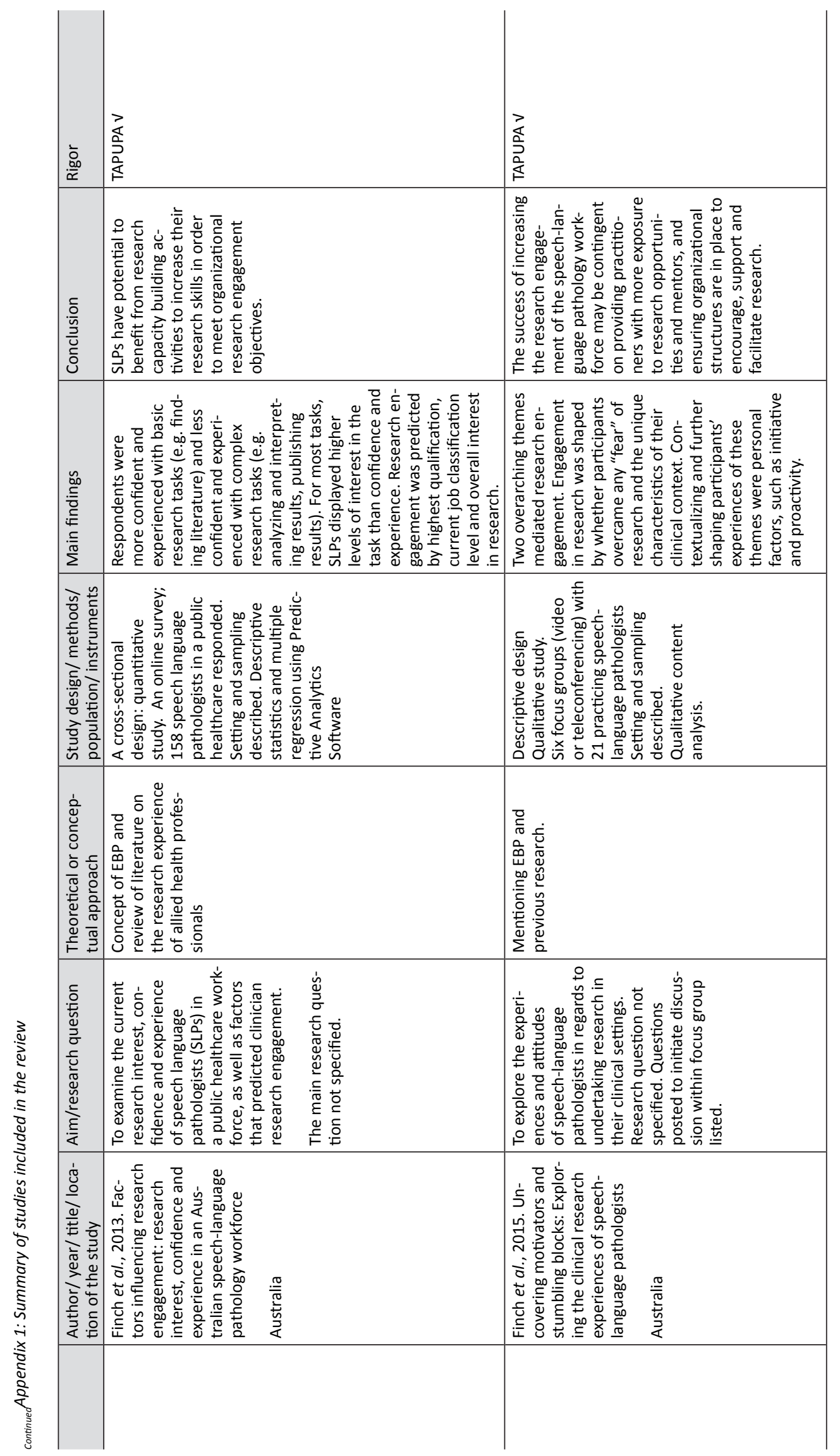




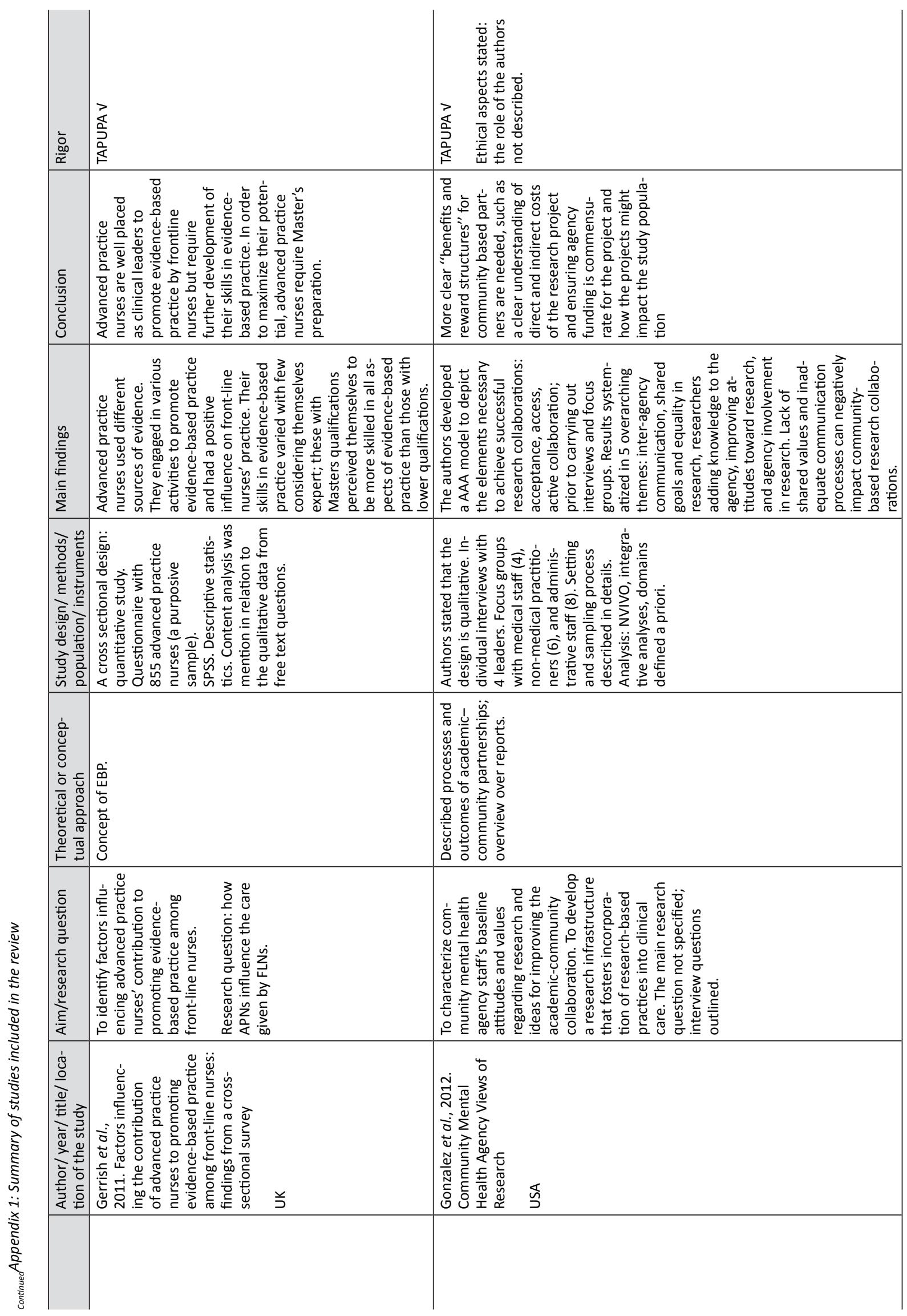




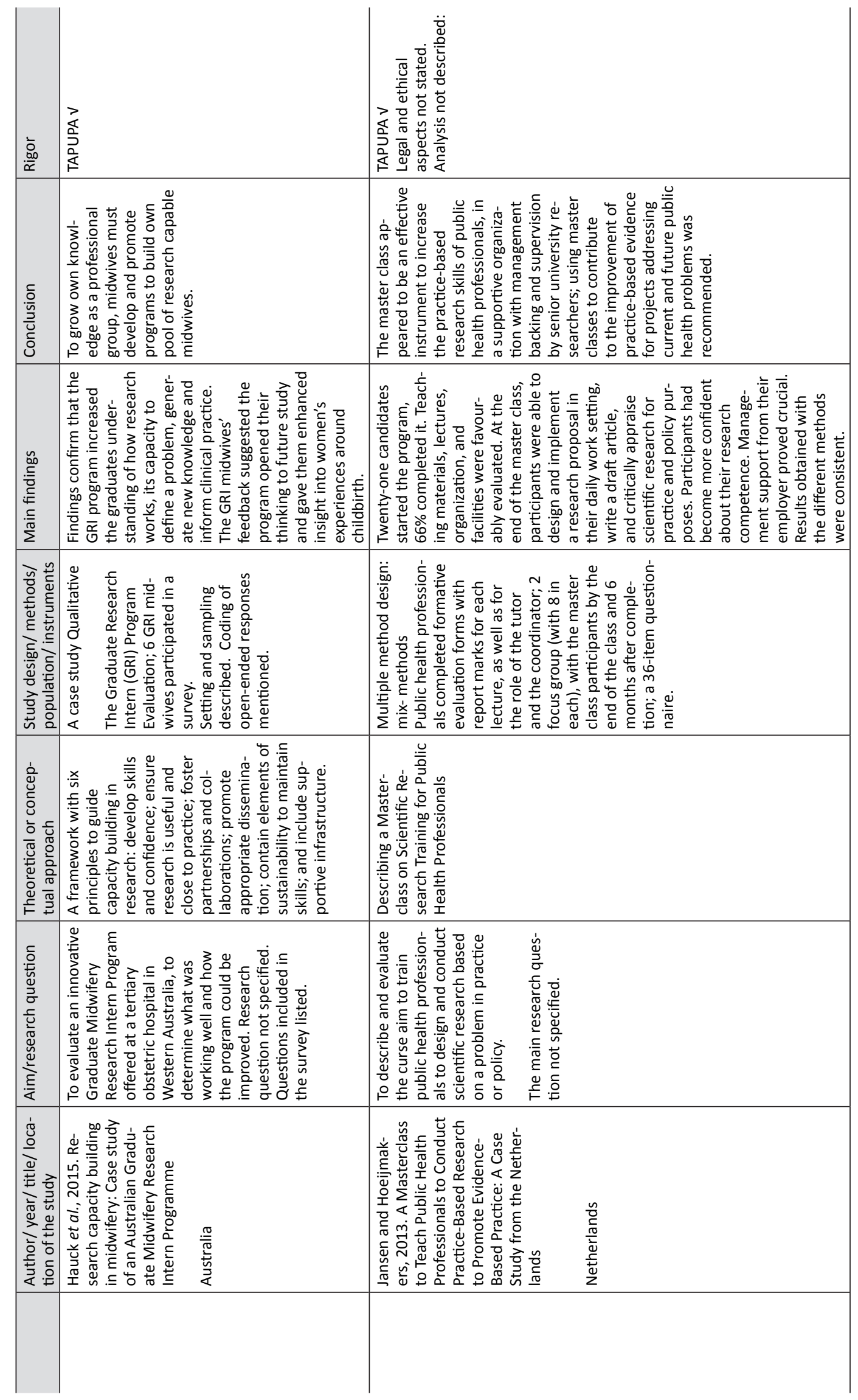




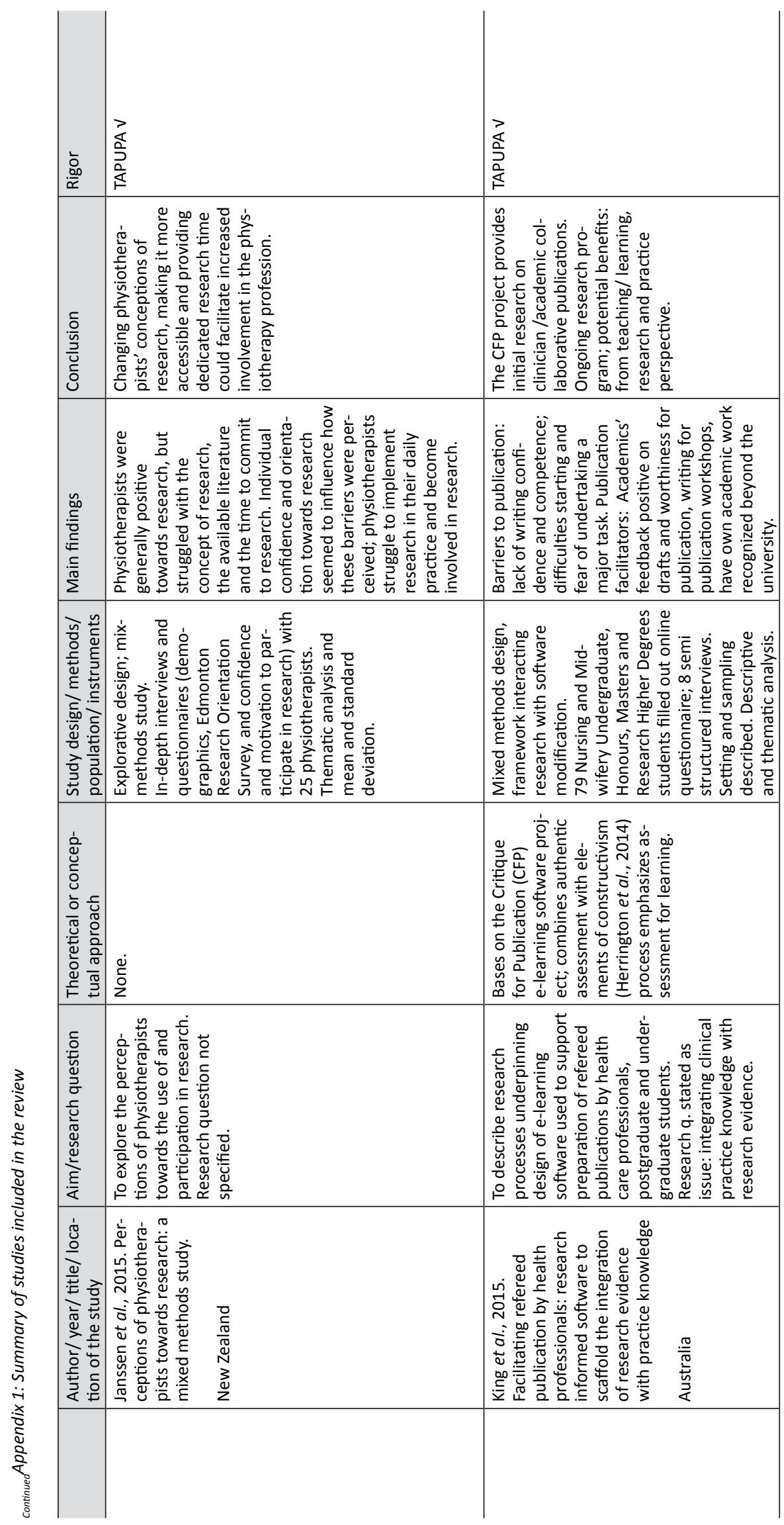




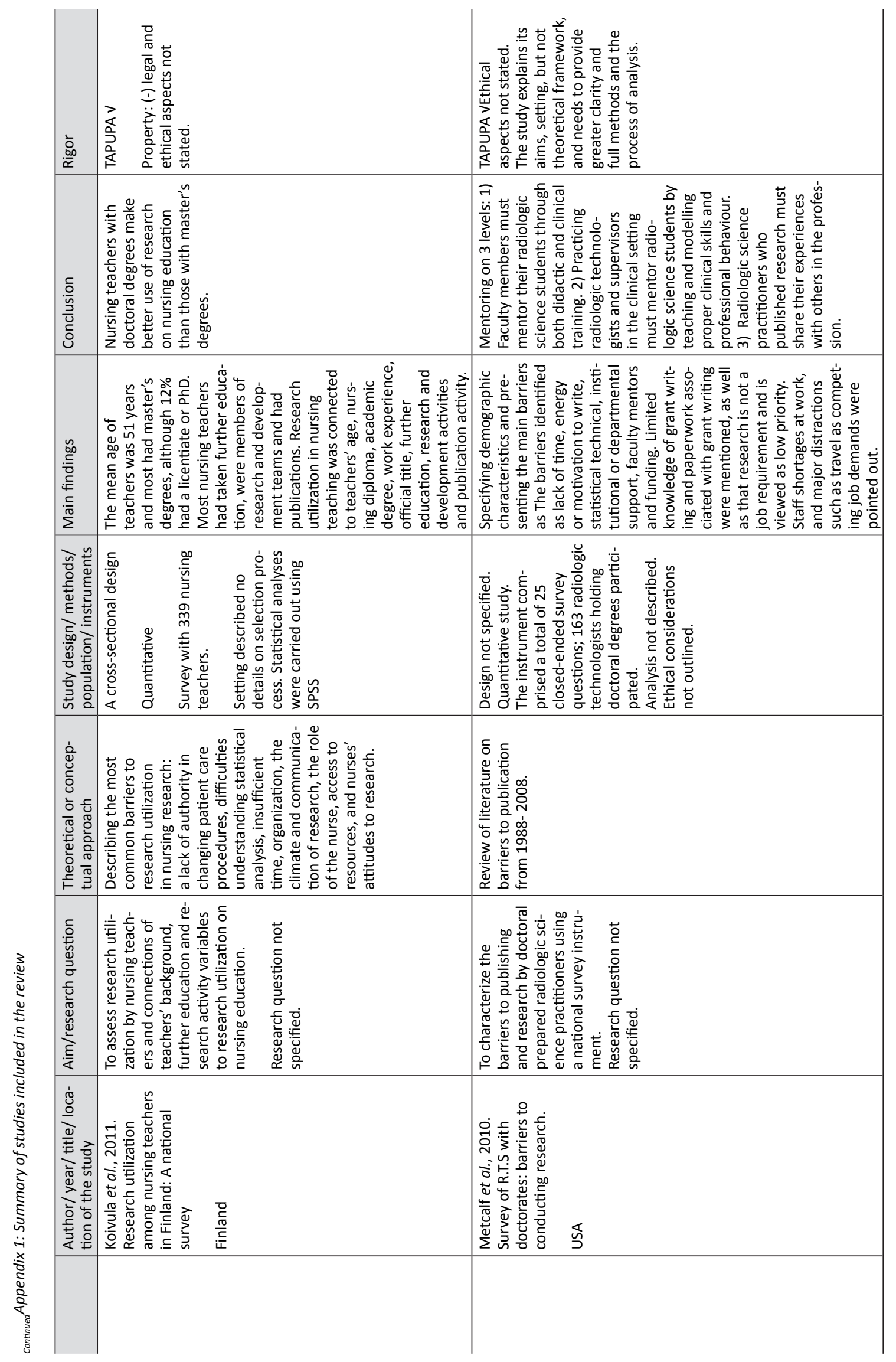




\begin{tabular}{|c|c|c|}
\hline 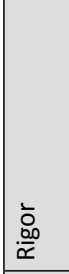 & 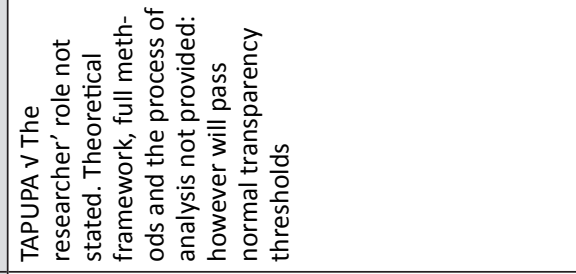 & 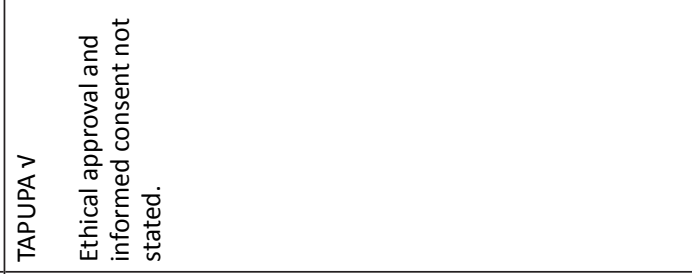 \\
\hline & 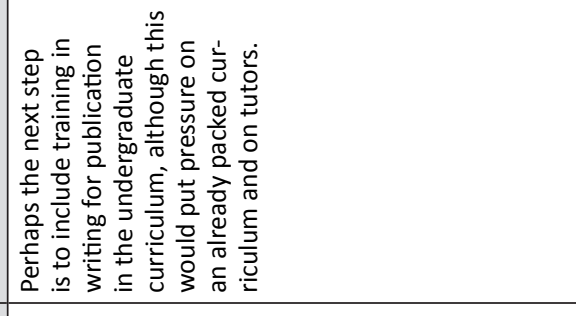 & 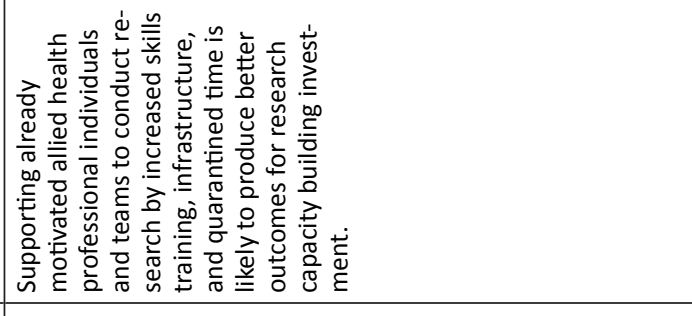 \\
\hline 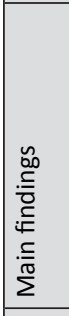 & 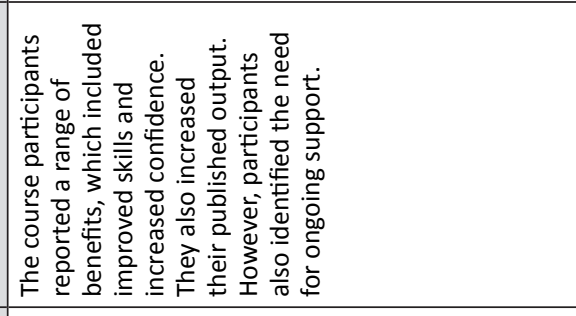 & 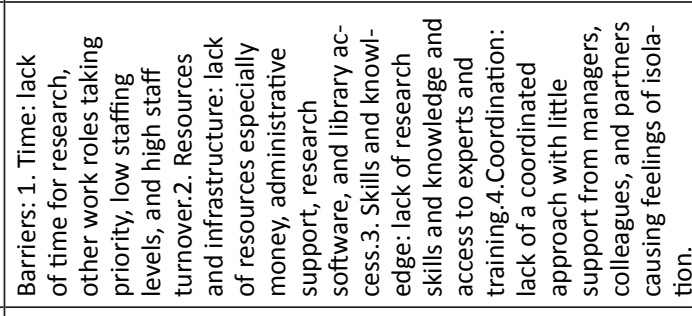 \\
\hline 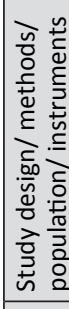 & 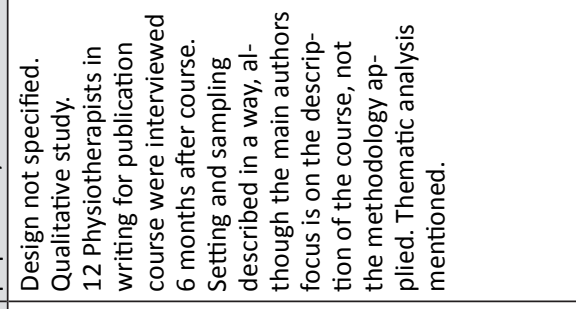 & 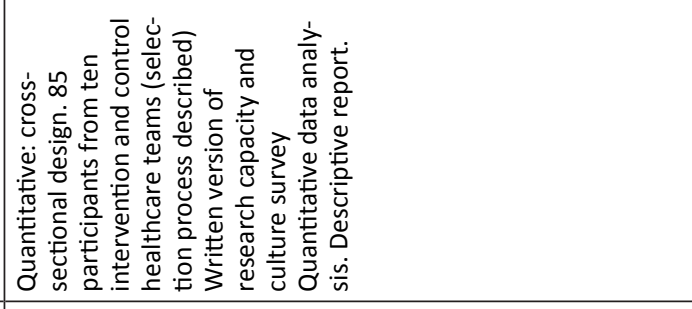 \\
\hline 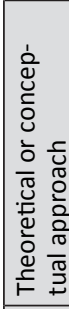 & 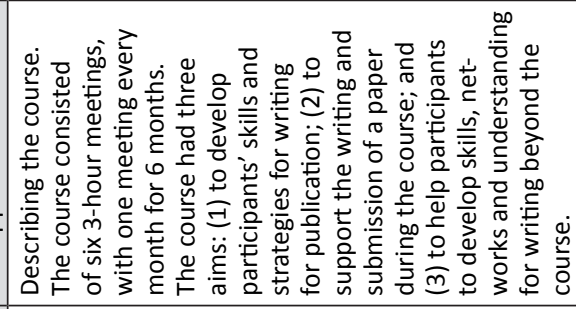 & 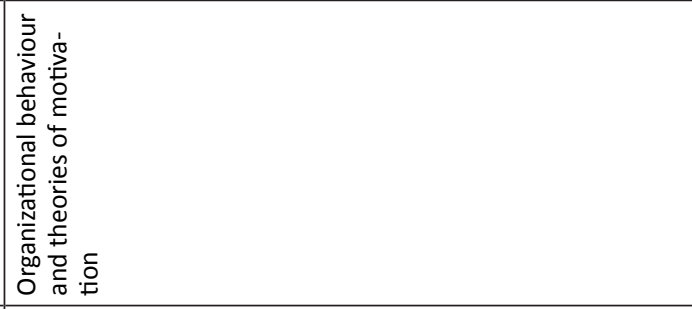 \\
\hline 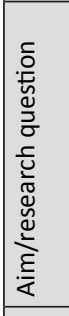 & 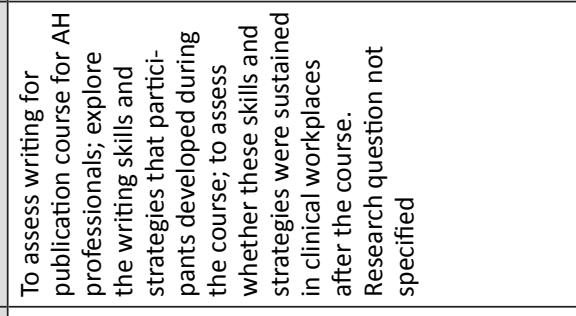 & 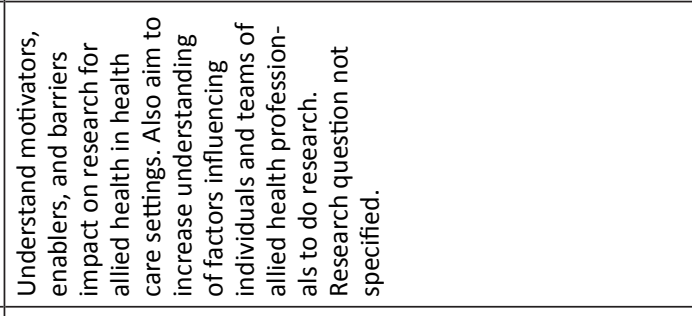 \\
\hline 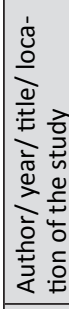 & 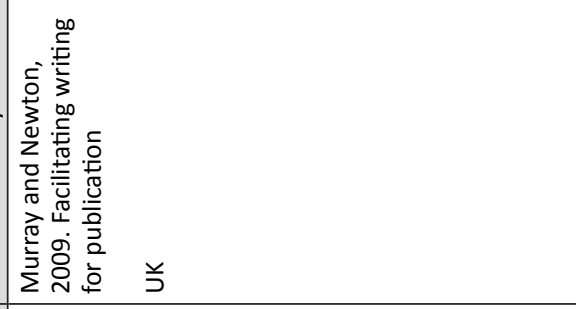 & 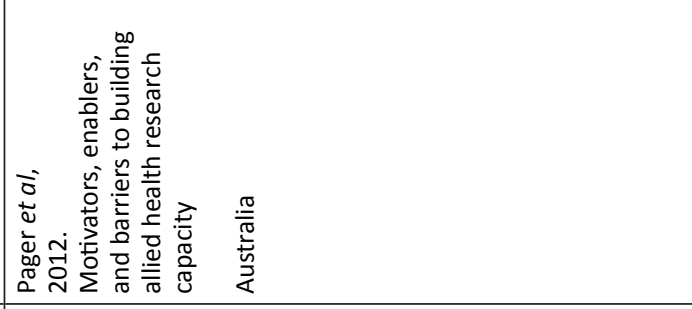 \\
\hline
\end{tabular}




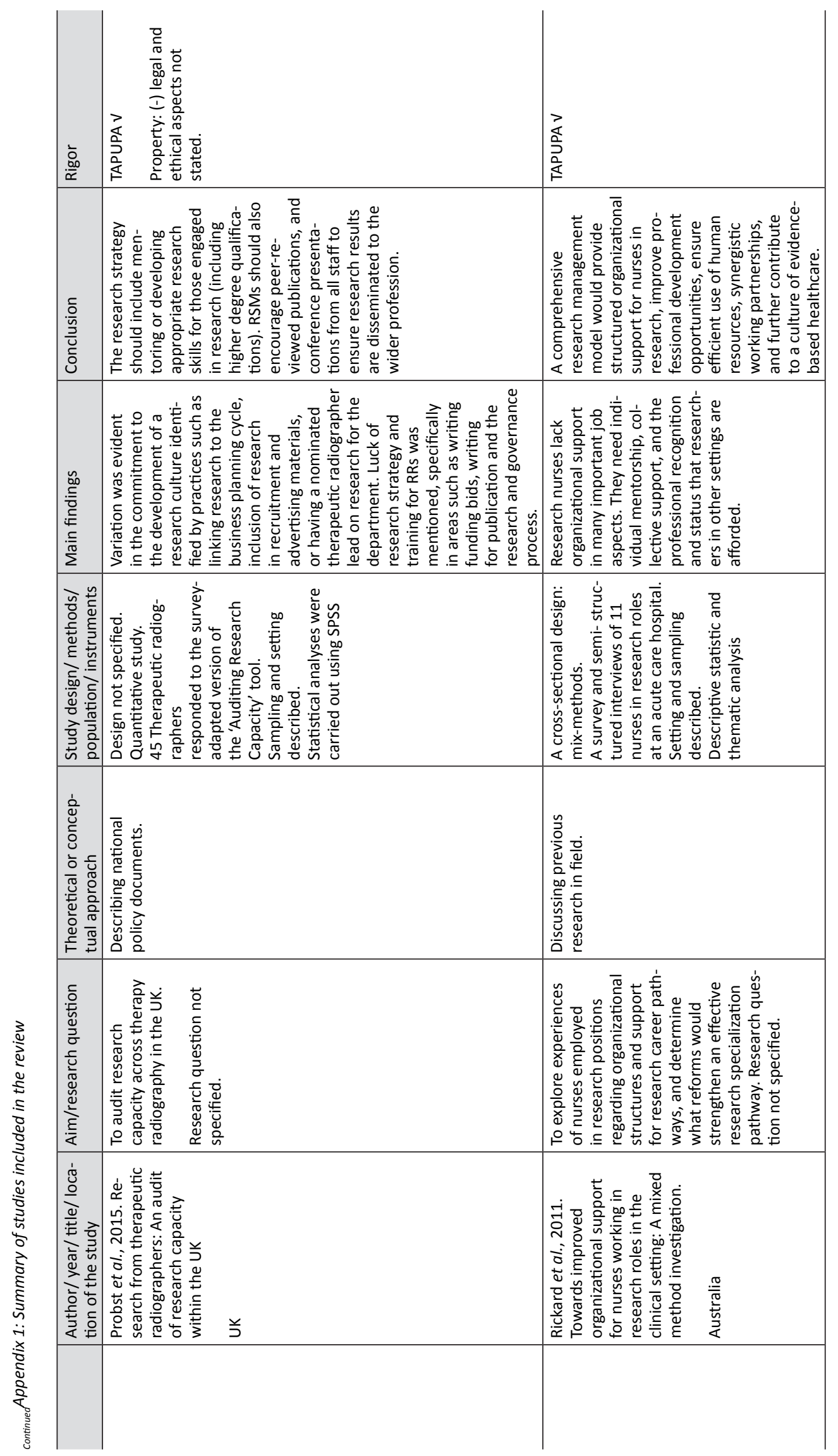




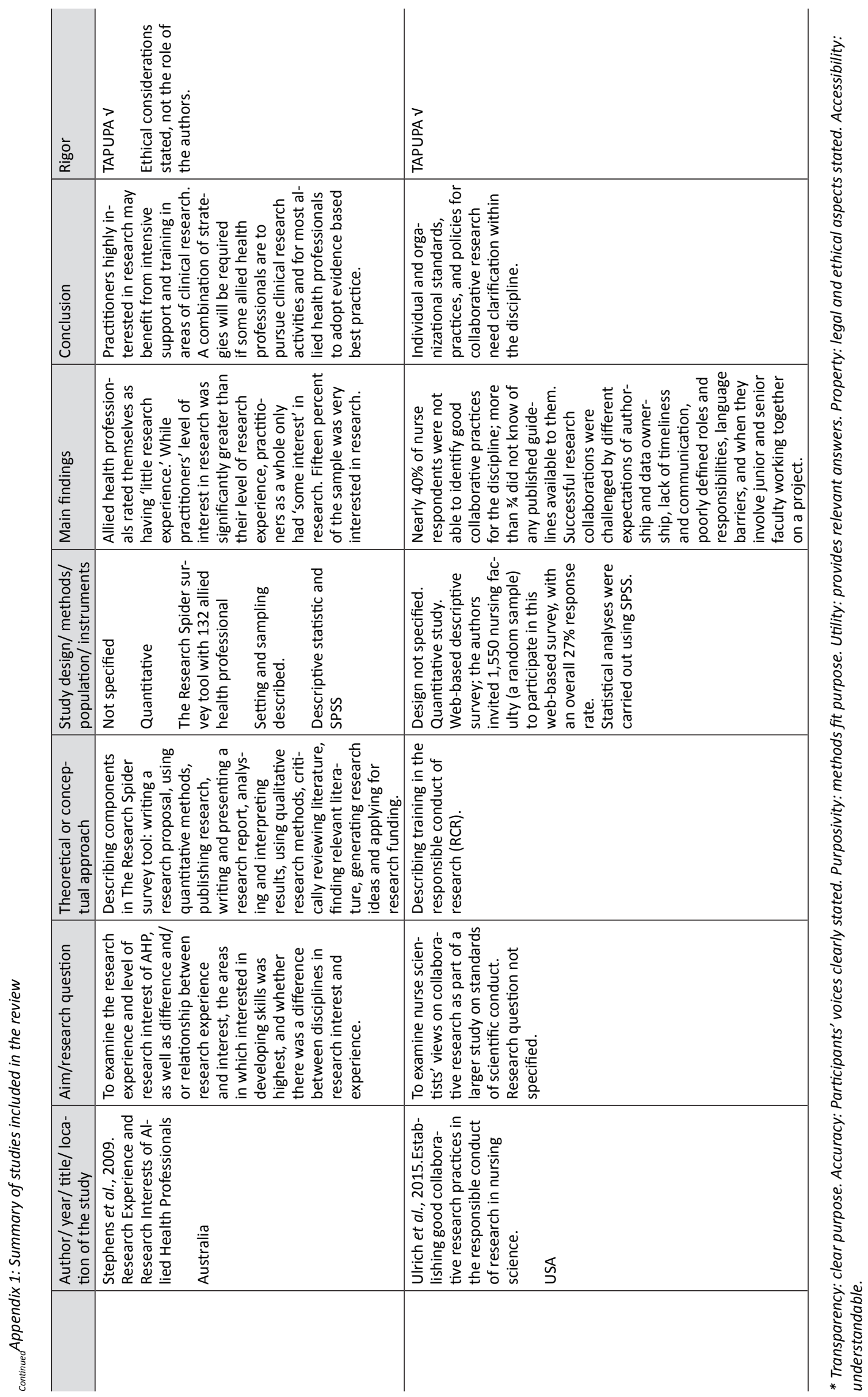

